\title{
THE ESTIMATION OF EPISTASIS IN COMPONENTS OF FITNESS IN EXPERIMENTAL POPULATIONS OF DROSOPHILA MELANOGASTER II. ASSESSMENT OF MEIOTIC DRIVE, VIABILITY, FECUNDITY AND SEXUAL SELECTION
}

\author{
A. G. CLARK* and M. W. FELDMAN \\ Department of Biological Sciences, Stanford University, Stanford, CA 94305 \\ Received 15.x.80
}

\section{SUMMARY}

\begin{abstract}
An analysis of fitness components was performed on laboratory populations of Drosophila melanogaster bearing Curly and Plum marked second chromosome inversions with two genetic backgrounds. Selective differences between Curly, Plum, Curly-Plum, and wild phenotypes were partitioned into meiotic drive, viability, fecundity and mating success. Although no significant meiotic drive was detected, there were significant differences between genotypes in the other three components. Interlocus interactions in fertility and sexual selection components were measured, and statistics to quantify epistasis at these levels of fitness were devised. Significant fitness interactions between genes on the Curly and Plum inversions in viability, fecundity, and sexual selection were found. These results were qualitatively consistent with the maximum likelihood fitness estimates found previously. The expected allele frequency trajectories computed from the estimated components adequately fitted the observed selection trajectories.
\end{abstract}

\section{INTRODUCTION}

DESPITE the massive effort that has been made to detect selective differences between electrophoretically identified enzyme loci, the results are discouraging. As Lewontin (1974) stated, the problem may be one of dimension. In an organism with $n$ polymorphic loci, the 1 locus marginal fitnesses may have very little to do with the way selection operates on that locus. In the case of 2 loci for example, heterozygote advantage in the marginal fitnesses is neither necessary nor sufficient for the maintenance of a polymorphism. Theoretical models tell us that in the absence of linkage disequilibrium and epistasis, single genes may be considered the units of selection. A central question in population genetics is therefore to what extent do selective differences between multi-locus genotypes depend on epistatic interactions? In this paper we report our attempts to detect the effects at a number of stages in the life cycle, of interactions in fitness between genes on linked inversions in Drosophila melanogaster.

Since Prout (1965) demonstrated that experimental measurement of fitness is best done by splitting the net fitness into components, there have been a number of studies which have used the technique of selection components analysis to assess fitness differences between genotypes (Prout, 1971a, 1971b; Bungaard and Christiansen, 1972; Clegg et al., 1978;

\footnotetext{
* Present address: Dept. of Zoology, Arizona State University, Tempe, AZ 85281
} 
Christiansen and Frydenburg, 1973; Christiansen, Frydenburg and Simonsen 1977, Curtsinger and Feldman, 1980; Østergaard and Christiansen, 1980). Although these studies partition selective effects by different techniques, the components measured generally fall into four categories, including meiotic drive, viability, sexual selection and fecundity. Differential production of gametes by heterozygotes is referred to as meiotic drive or gametic selection. Ideally this would be measured by scoring the haplotype frequencies of gametes, but in practice it is inferred from zygote frequencies. Viability or zygotic selection refers to differences in egg-to-adult survival, and it is usually measured by observing deviations from expected Mendelian ratios among progeny when parental genotypes are known. Mating and fertility components have been measured in a variety of ways. Fecundity selection is manifested by differential production of offspring, and can be measured in Drosophila by isolating females inseminated by known males in shell vials and scoring eggs or progeny. Sexual selection indices describe the differential ability of genotypes of either sex to attract mates, and this type of selection is measured by comparing the frequency of genotypes which mate to those which do not mate. When comparing visible mutants of Drosophila this is easily done by placing known frequencies of virgins in a mating chamber for a predetermined time, and scoring mating types either by direct observation or by inference from progeny sets. In the field one can assess components of fertility in some organisms by comparing genotype frequencies among males, nongravid females, gravid females and their progeny (Christiansen and Frydenburg, 1973).

Laboratory studies of wild caught flies (Sved and Ayala, 1970; Tracey and Ayala, 1974; Sved, 1971, 1975) have indicated that fertility components account for most of the fitness loss of chromosomal homozygotes. Fertility components also seem to dominate net fitness effects in laboratory stocks of Drosophila (Prout, 1971 $a$; Bungaard and Christiansen, 1972; Wilson, 1968). Mutagenized Drosophila also suffer greater loss in fertility than in viability (Mitchell and Simmons, 1977; Simmons et al., 1978). Despite the agreement that fertility is a significant fitness component, there has yet to appear a study designed to measure interactions between identified genes affecting fertility. Quantitative genetic methods, on the other hand, commonly reveal significant epistatic components of variance in fertility traits (Kearsey and Kojima, 1967; Broadhurst and Jinks, 1974; Mather, 1973), and it is thought that the genetic architecture reflects the past operation of selection.

Several attempts to detect epistasis in viability of wild chromosomes of Drosophila have been made by analysing progeny ratios from crosses which yield flies isogenic for the second chromosome, the third chromosome or co-isogenic for both (Spassky et al., 1965; Temin et al. 1969; Kosuda, 1971; Tsuno, 1970). The general conclusion of these studies is that the double homozygote viability is slightly lower than expected from the single homozygote fitnesses, i.e., there is positive epistasis, although Temin et al., (1969) found the epistasis to be insignificant. Tsuno (1970) demonstrated that the strength of epistasis depended on the single homozygote fitnesses. Keller and Mitchell (1964) demonstrated X-autosome interactions in viability by crossing between inbred lines. Although these studies give insight into the importance of epistasis in wild chromosomes, they are limited in that they do not address fertility components. More recently 
however, Seager (1979) assessed viability interactions and net fitnesses in cage competition experiments, and found that viability effects did not explain the cage trajectories.

In this paper we use the techniques of selection components analysis to assess fitnesses of genotypes of Drosophila melanogaster that differ by large blocks of genes on second chromosome inversions marked by the phenotypically dominant homozygous lethal alleles Curly and Plum. By measuring differences in viability and fertility components we have determined the extent to which genes on these two inversions interact at the four levels of fitness.

\section{MATERIALS AND METHODS}

The stocks employed in this study were the same as those used in the previous paper in this series (Clark et al., 1981). Stocks of $\mathrm{Cy}, \mathrm{Pm}^{1}, \mathrm{Pm}^{2}$, $\mathrm{Cy} / \mathrm{Pm}^{1}, \mathrm{Cy} / \mathrm{Pm}^{2}$ (trans double heterozygotes), $\mathrm{Cy}-\mathrm{Pm}^{2}$ (cis double heterozygotes) and wild type were generated with both homogeneous and heterogeneous background, where homogeneous stocks were isogenic for the $\mathrm{X}$ and segments of the second chromosome. The stocks were maintained in half-pint bottles on Carolina 4-24 instant Drosophila medium (12 g medium, $35 \mathrm{ml}$ water and a dash of live yeast). Mating, egg laying, and development occurred in an incubator with a $12 \mathrm{hr}$ day $/ 12 \mathrm{hr}$ night cycle at $25 \pm 1^{\circ} \mathrm{C}$

\section{(i) The general paradigm}

The four components of fitness were estimated from the following experiment. On day 0 fifty male and fifty female 4 day old virgins of 2 phenotypes were placed in a half-pint bottle for 2 hours. After this time it was found that most of the females had been inseminated, while there was not sufficient time for multiple matings (Bungaard and Christiansen, 1972). Multiple inseminations could have been inferred from progeny of individual females. After mating, the flies were anesthetized and the males were discarded. Individual females were placed in $95 \mathrm{~mm}$ shell vials with $1.5 \mathrm{~g}$ Carolina 4-24 medium, $5 \mathrm{ml}$ water and yeast. Egg laying occurred through day 4 at which time the females were discarded. Eighteen days after egg laying began, adult progeny were scored. The frequencies of the different mating types were obtained from the known maternal types and the paternal types inferred from the progeny. From mating frequencies we obtained measures of sexual selection and randomness of mating. Fecundity was measured by comparing the numbers of adult progeny produced by each mating type. Meiotic drive and viability differences were inferred by deviations from expected Mendelian ratios among progeny. Whenever significance is tested by analysis of variance, we verify that distributions are normal with homogeneous variance.

\section{(ii) Meiotic drive}

Consider the general paradigm experiment in which the two genotypes tested were $\mathrm{Cy}$ and wild. The mating $\mathrm{Cy} \times$ wild will produce $\mathrm{Cy}$ and wild progeny with an expected ratio of $1: 1$. Due to meiotic drive in the female, 
and/or viability selection, this ratio may be distorted. Let us say that the observed ratio of $\mathrm{Cy}$ to wild progeny is $k_{1}: 1$. Wild $\times \mathrm{Cy}$ matings will also produce these two types of progeny in relative proportions of, say, $k_{2}: 1$. Let the progeny ratio in the $\mathrm{Cy} \times \mathrm{Cy}$ matings be $2 k_{3}: 1$. The relations between $k_{1}, k_{2}$, and $k_{3}$ will allow us to partition the effects into meiotic drive and viability differences. If $k_{1}=k_{2}=k_{3} \neq 1$, there is either viability selection operating with no meiotic drive, or else the degree of segregation distortion is the same in both sexes. These two possibilities cannot be distinguished by this experimental procedure. If $k_{2}=k_{3} \neq k_{1}=1$, then there is no viability selection operating, and the males show distorted segregation. If $1=k_{2} \neq$ $k_{3}=k_{1}$, then there is either meiotic drive operating in the females, or there is a maternal effect on viability. If we reject the first null hypothesis $\left(k_{1}=k_{2}=\right.$ $k_{3}$ ), then it may not be possible by this technique to precisely assess the relative importance of viability and meiotic drive because the effects are confounded. If, however, the first null hypothesis is not rejected then there is no evidence for meiotic drive and we accept that deviant segregations are due to viability differences (ignoring the unlikely possibility of equal segregation distortion in both sexes). The importance of segregation distortion could be more accurately assessed if we could sample progeny zygotes as early as possible to minimize viability differences. For visible markers such as Cy and Pm, it is doubtful that this would be worthwhile, since there is considerable opportunity for viability selection to occur in the larval stages.

The mean and variance of segregation ratios can be calculated in two ways: we can either weight the observed segregation in each progeny set by the respective number of progeny, or use the unweighted estimators. As Engels (1979) pointed out, if the observed variance is sufficiently greater than the expected binomial variance, then the unweighted estimators are preferred, because they are unbiased and more efficient. The variances observed here in segregation ratios were greater than the expected binomial variance, so the estimators of meiotic drive and viability reported here are unweighted.

Epistasis in meiotic drive is complicated by the fact that there is more than one degree of freedom, even in our linked lethal experimental design. For every heterozygous genotype, there is an associated drive parameter which represents the relative frequency of the two chromosome types in that individual's gametes. If the drive parameter for $\mathrm{Cy} /+$ heterozygotes were $k_{1}$, and the parameter for $\mathrm{Pm}^{2} /+$ were $k_{2}$, then we could designate epistasis in meiotic drive as the deviation from $k_{1}+k_{2}$ or $k_{1} k_{2}$ in the parameter of $\mathrm{CyPm}^{2} /++$ individuals. In addition there could be distorted segregation in $\mathrm{Cy} / \mathrm{Pm}^{2}$ individuals, giving a fourth independent meiotic drive parameter. In the case of 2 diallelic loci without lethal alleles, there are 4 single heterozygotes and 2 double heterozygotes, so to completely describe the segregation requires a matrix of 6 drive parameters.

\section{(iii) Viability}

Estimates of relative viability were obtained by deviations from Mendelian segregation among progeny of known matings after meiotic drive had been ruled out. Note that we use the term viability selection to refer only to relative frequencies in the progeny, and that viability in this sense is strictly independent of the total number of progeny a female produces. 
TABLE 1

Viability crosses. Each cross in the table yields information about the relative viability of the genotypes in the

\begin{tabular}{|c|c|c|c|c|c|c|}
\hline & $\mathrm{Pm}^{1}$ & $\mathrm{Pm}^{2}$ & $\mathrm{Cy} / \mathrm{Pm}^{1}$ & $\mathrm{Cy} / \mathrm{Pm}^{2}$ & Cy-Pm ${ }^{2}$ & wild \\
\hline $\mathrm{Cy}$ & $\begin{array}{l}\mathrm{Cy} \times \mathrm{Pm}^{1} \\
\mathrm{Pm}^{1} \times \mathrm{Cy} \\
\mathrm{Cy} / \mathrm{Pm}^{1} \times \text { wild } \\
\text { wild } \times \mathrm{Cy} / \mathrm{Pm}^{1} \\
\mathrm{Cy} \times \mathrm{Cy} / \mathrm{Pm}^{1} \\
\mathrm{Cy} / \mathrm{Pm}^{1} \times \mathrm{Cy} \\
\mathrm{Pm}^{1} \times \mathrm{Cy}^{1} / \mathrm{Pm}^{1} \\
\mathrm{Cy} / \mathrm{Pm}^{1} \times \mathrm{Pm}^{1}\end{array}$ & $\begin{array}{l}\mathrm{Cy} \times \mathrm{Pm}^{2} \\
\mathrm{Pm}^{2} \times \mathrm{Cy}^{2} \\
\mathrm{Cy} / \mathrm{Pm}^{2} \times \text { wild } \\
\text { wild } \times \mathrm{Cy} / \mathrm{Pm}^{2} \\
\mathrm{Cy}-\mathrm{Pm}^{2} \times \text { wild } \\
\mathrm{Cy} \times \mathrm{Cy} / \mathrm{Pm}^{2} \\
\mathrm{Pm}^{2} \times \mathrm{Cy} / \mathrm{Pm}^{2}\end{array}$ & $\begin{array}{l}\mathrm{Cy} \times \mathrm{Pm}^{1} \\
\mathrm{Pm}^{1} \times \mathrm{Cy} \\
\mathrm{Cy} \times \mathrm{Cy} / \mathrm{Pm}^{1} \\
\mathrm{Cy} / \mathrm{Pm}^{1} \times \mathrm{Cy}^{1} \\
\mathrm{Pm}^{1} \times \mathrm{Cy} / \mathrm{Pm}^{1} \\
\mathrm{Cy} / \mathrm{Pm}^{1} \times \mathrm{Pm}^{1}\end{array}$ & $\begin{array}{l}\mathrm{Cy} \times \mathrm{Pm}^{2} \\
\mathrm{Pm}^{2} \times \mathrm{Cy} \\
\mathrm{Cy} \times \mathrm{Cy} / \mathrm{Pm}^{2} \\
\mathrm{Pm}{ }^{2} \times \mathrm{Cy} / \mathrm{Pm}^{2}\end{array}$ & $\mathrm{Cy} \times \mathrm{Cy}-\mathrm{Pm}^{2}$ & $\begin{array}{l}\mathrm{Cy} \times \text { wild } \\
\text { wild } \times \mathrm{Cy} \\
\mathrm{Cy} \times \mathrm{Cy} \\
\mathrm{Cy} \times \mathrm{Pm}^{1} \\
\mathrm{Pm}^{1} \times \mathrm{Cy} \\
\mathrm{Cy} \times \mathrm{Pm}^{2} \\
\mathrm{Pm}^{2} \times \mathrm{Cy} \\
\mathrm{Cy} \times \mathrm{Cy}-\mathrm{Pm}^{2}\end{array}$ \\
\hline $\mathrm{Pm}^{1}$ & & & $\begin{array}{l}\mathrm{Cy} \times \mathrm{Pm}^{1} \\
\mathrm{Pm}^{1} \times \mathrm{Cy} \\
\mathrm{Cy} \times \mathrm{Cy} / \mathrm{Pm}^{1} \\
\mathrm{Cy} / \mathrm{Pm}^{1} \times \mathrm{Cy}^{1} \\
\mathrm{Pm}^{1} \times \mathrm{Cy} / \mathrm{Pm}^{1} \\
\mathrm{Cy} / \mathrm{Pm}^{1} \times \mathrm{Pm}^{1}\end{array}$ & & & $\begin{array}{l}\mathrm{Pm}^{1} \times \mathrm{Pm}^{1} \\
\mathrm{Cy} \times \mathrm{Pm}^{1} \\
\mathrm{Pm}^{1} \times \mathrm{Cy} \\
\mathrm{Pm}^{1} \times \text { wild } \\
\text { wild } \times \mathrm{Pm}^{1}\end{array}$ \\
\hline $\mathrm{Pm}^{2}$ & & & & $\begin{array}{l}\mathrm{Cy} \times \mathrm{Pm}^{2} \\
\mathrm{Pm}{ }^{2} \times \mathrm{Cy} \\
\mathrm{Cy} \times \mathrm{Cy} / \mathrm{Pm}^{2} \\
\mathrm{Pm}^{2} \times \mathrm{Cy} / \mathrm{Pm}^{2}\end{array}$ & $\mathrm{Pm}^{2} \times \mathrm{Cy}-\mathrm{Pm}^{2}$ & $\begin{array}{l}\mathrm{Pm}^{2} \times \mathrm{Pm}^{2} \\
\mathrm{Pm}^{2} \times \text { wild } \\
\text { wild } \times \mathrm{Pm}^{2} \\
\mathrm{Cy} \times \mathrm{Pm}^{2} \\
\mathrm{Pm}^{2} \times \mathrm{Cy} \\
\mathrm{Pm}^{2} \times \mathrm{Cy}-\mathrm{Pm}^{2}\end{array}$ \\
\hline $\mathrm{Cy} / \mathrm{Pm}^{1}$ & & & & & & $\begin{array}{l}\mathrm{Cy} \times \mathrm{Pm}^{1} \\
\mathrm{Pm}^{1} \times \mathrm{Cy}\end{array}$ \\
\hline $\mathrm{Cy} / \mathrm{Pm}^{2}$ & & & & & & $\begin{array}{l}\mathrm{Cy} \times \mathrm{Pm}^{2} \\
\mathrm{Pm}^{2} \times \mathrm{Cy}\end{array}$ \\
\hline $\mathrm{Cy}-\mathrm{Pm}^{2}$ & & & & & & $\begin{array}{l}\mathrm{Cy}-\mathrm{Pm}^{2} \times \text { wild } \\
\text { wild } \times \mathrm{Cy}-\mathrm{Pm}^{2} \\
\mathrm{Cy} \times \mathrm{Cy}-\mathrm{Pm}^{2} \\
\mathrm{Pm}^{2} \times \mathrm{Cy}-\mathrm{Pm}^{2}\end{array}$ \\
\hline
\end{tabular}

Several different crosses may yield information about the relative viability of two genotypes (table 1), and tests were applied to these data to see whether the viability estimates were homogeneous. Heterogeneity could be due to several factors, and these were tested independently. Presence of larval competition was tested by comparing for example the $\mathrm{Cy}$ : wild viability in crosses which had only $\mathrm{Cy}$ and wild progeny to crosses such as $\mathrm{Cy} \times \mathrm{Pm}^{1}$ in which progeny of four classes were obtained. Density dependence in viability was tested by performing regressions of apparent viability on the number of flies per progeny set. Maternal or cytoplasmic effects were tested by comparing viabilities of 2 genotypes with different maternal types. Relative viabilities of two genotypes may depend on sex, and this was tested by comparing segregation ratios among female and male progeny. As table 1 indicates, we can independently measure the cis and trans double heterozygote viabilities, and differences between them would indicate position effects. Internal checks of the viability measures were performed by comparing ratios of the viability estimates. The relative viability of, for example, $\mathrm{Cy}: \mathrm{Pm}^{1}$ should equal the ratio of $\mathrm{Cy}$ : wild viability to $\mathrm{Pm}^{1}$ : wild viability. All tests were replicated extensively, and empirical standard errors are reported.

From the viability measures, estimates of epistasis were made. Suppose that the $\mathrm{Cy}$ :wild viability is $v_{1}$, the $\mathrm{Pm}^{1}$ : wild viability is $v_{2}$, and the $\mathrm{Cy} / \mathrm{Pm}^{1}$ : wild viability is $v_{3}$, then the multiplicative epistasis, defined as 
$\ln \left(v_{3} / v_{1} v_{2}\right)$, measures the departure from multiplicativity of fitness effects of $\mathrm{Cy}$ and $\mathrm{Pm}^{1}$ in determining the $\mathrm{Cy} / \mathrm{Pm}^{1}$ viability. The additive epistasis, defined as $1-v_{1}-v_{2}+v_{3}$, measures the departure from additivity of deleterious effects. Note that a position effect in viability leads to two multiplicative and two additive measures of viability epistasis, since there is a different $v_{3}$ associated with each of the two types of double heterozygote.

The significance of epistasis was tested by constructing 95 per cent confidence intervals. If viabilities $v_{1}, v_{2}$ and $v_{3}$ are independent and distributed normally with means $v_{1}, v_{2}$ and $v_{3}$ and variances $\sigma_{1}^{2}, \sigma_{2}^{2}, \sigma_{3}^{2}$, then the quantity $E(A)=1-v_{1}-v_{2}+v_{3}$ is distributed normally with mean $1-$ $\bar{v}_{1}-\bar{v}_{2}+\bar{v}_{3}$ and variance $\sigma_{1}^{2}+\sigma_{2}^{2}+\sigma_{3}^{2}$. If the sample sizes of each experiment to determine viability were $n_{1}, n_{2}$ and $n_{3}$, and sample variances were $s_{1}^{2}, s_{2}^{2}$, and $s_{3}^{2}$ respectively, then the confidence interval for the additive epistasis is approximately

$$
\left[\left(1-\bar{v}_{1}-\bar{v}_{2}+\bar{v}_{3}\right) \pm z_{\alpha} \sqrt{\left.\left(s_{1}^{2} / n_{1}\right)+\left(s_{2}^{2} / n_{2}\right)+\left(s_{3}^{2} / n_{3}\right)\right)}\right]
$$

If this does not contain zero, then there is additive epistasis at the level of significance $\alpha$. A similar approximate confidence interval for the multiplicative epistasis, $\ln \left(v_{3} / v_{1} v_{2}\right)$, can be constructed by first log transforming the data.

(iv) Fecundity

The measure of fecundity is simply the mean number of adult progeny produced per singly inseminated female by the 18th day after egg laying commenced. Confounded in this measure are egg production, egg hatchability, and absolute viability effects, but this does not reduce the predictive accuracy of the estimate. Since most of the variance in egg hatchability is maternally inherited (Chapco and Ebisuzaki, 1978), there is good reason to include these components in the maternal fecundity (see Discussion). For each experiment described in the general paradigm, we obtain a distribution of fecundities from each of the four possible mating types. Two-way analysis of variance was performed on these data to assess female and male effects, as well as mating interactions. In addition, fecundities of like mating types were tested for homogeneity and normality, and then pooled. These pooled fecundities were then put in mating tables in the format of table 2. A maximum likelihood routine was written to calculate the $m_{i}$ and $f_{i}$ parameters to give the best fit of the additive and multiplicative fecundity models to the data.

Interactions in fecundity can occur at two levels. Female $\times$ male interactions occur when fecundities of matings are not explained by a sum or product of male and female effects. In the $\mathrm{Cy} \times$ wild experiment, for instance, suppose the fecundities are normalized to the wild $\times$ wild cross. We obtain an estimate of $f_{1}$ from the $\mathrm{Cy} \times$ wild cross (see table 2 ) and of $m_{1}$ from the wild $\times$ Cy cross. If fecundities are multiplicative, the $\mathrm{Cy} \times \mathrm{Cy}$ cross would have a fecundity of $f_{1} m_{1}$. Failure to fit this model would indicate interaction between sexes. In the absence of this type of interaction, there may still be epistasis, and it can be expressed independently in the two sexes. Using the notation of table 2 , one of the male multiplicative fecundity epistasis measures is $\ln \left(m_{3} / m_{1} m_{2}\right)$, while that of the female is $\operatorname{In}\left(f_{3} / f_{1} f_{2}\right)$. If there were male $\times$ female interactions, epistasis could not be partitioned separately into the two sexes. Since the fecundity data are fitted for two 
TABLE 2

Matrix format for fecundity models. With $\mathrm{Pm}^{2}$ there are two double heterozygotes so the matrices are $5 \times 5$ and there are 2 more parameters

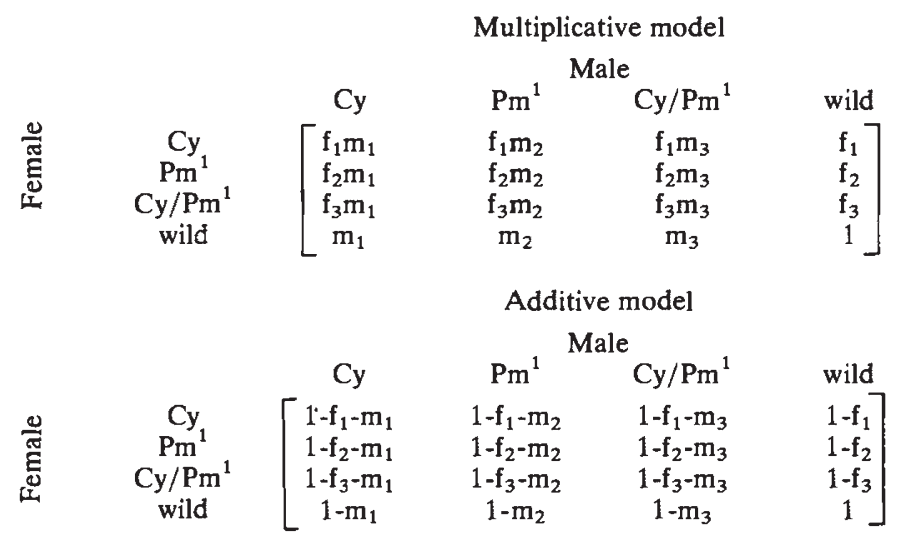

sexes in two backgrounds to both an additive and multiplicative model, there are a total of 8 epistasis measures in the $\mathrm{Cy} / \mathrm{Pm}^{1}$ system. With $\mathrm{Pm}^{2}$ the two double heterozygotes may also show a position effect in fecundity, so in this case there are 16 epistasis parameters. Significance of epistasis in fecundity is assessed using approximate confidence intervals analogous to those for viability.

\section{(v) Sexual selection}

Using the general paradigm, $2 \times 2$ tables of mating type frequency were constructed for each pair of genotypes (table 3 ). The test for random mating among individuals who did mate is simply the contingency chisquare. If $n_{1}$ Cy and $n_{2}$ wild were introduced initially (with equal numbers of both sexes), our male sexual selection index is $n_{2}(a+c) / n_{1}(b+d)$, while the female index is $n_{2}(a+b) / n_{1}(c+d)$. When $n_{1}=n_{2}$ this index is the ratio of $p / q$, where $p$ is the proportion of the mated males that are $\mathrm{Cy}$, and $q=1-p$. We assume that the distribution of mating types is multinomial and this allows us to estimate variances of the sexual selection indices. Using an approximation of Kendall and Stuart (1958, p. 233), if $n_{1}=n_{2}$ then $\operatorname{cov}(p, q)=-p q / N$, and we obtain:

$$
\operatorname{var}(p / q)=(p / q)^{2}[(q / p N)+(p / q N)+(2 / N)]
$$

\section{TABLE 3}

Matrix of mating type frequencies used to assess sexual selection indicies

$$
\begin{aligned}
& \text { Male }
\end{aligned}
$$

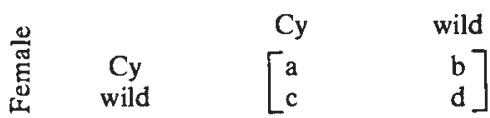


where $N=n_{1}+n_{2}$. If $n_{1} \neq n_{2}$ the mating index is $p n_{2} / q n_{1}$, with approximate variance,

$$
\operatorname{var}\left(p n_{2} / q n_{1}\right)=\left(n_{2} / n_{1}\right)^{2} \operatorname{var}(p / q)
$$

This approximation can be used to estimate confidence intervals and test the significance of sexual selection indices. Mating tests were done at a number of different phenotype frequencies to assess the importance of rare male effects on mating success.

Epistasis in sexual selection parameters was measured by comparing sexual selection indices of single and double heterozygotes. If for instance the index for $\mathrm{Cy}$ : wild is $s_{1}$, and that for $\mathrm{Pm}^{1}$ : wild is $s_{2}$, and the index for $\mathrm{Cy} / \mathrm{Pm}^{1}$ : wild is $s_{3}$, a measure of multiplicative epistasis in sexual selection is $\ln \left(s_{3} / s_{1} s_{2}\right)$. The significance of the interactions in sexual selection was assessed with an odds ratio test, where the odds ratio is defined as,

$$
\frac{\mathrm{P} \text { [observed double heterozygote sex. sel. index } \mid \text { epistasis }]}{\mathrm{P} \text { [observed double heterozygote sex. sel. index } \mid \text { no epistasis] }}
$$

where the probabilities are the binomial probabilities whose binomial parameters are determined by the single heterozygote sexual selection indices.

\section{(vi) Verification of components: trajectory comparisons}

The validity of the selection components was tested by generating expected genotype frequency trajectories based on estimated fitness components and checking their correspondence to observed selection trajectories. Populations were maintained in half pint bottles on an 18 day discrete generation protocol. Six different initial genotype frequencies were used, and four replicates of each treatment were followed. The details of these experiments are outlined in Clark et al. (1981). the system of recursions giving genotype frequencies as functions of the selection components for two loci is very similar to the one locus model given by Prout (1969). The main difference is that our two locus system has five genotypes instead of the three genotypes found in the single diallelic locus case. The Mendelian operators used by Prout must be increased in dimension and include terms involving the recombination rate. The recursion is:

$$
g_{k}^{\prime}=\frac{v_{k} \sum_{i} \sum_{j} g_{i} g_{j} S_{f i} S_{m j} F_{i j} K_{i j k}}{\sum_{k} v_{k} \sum_{i} \sum_{j} g_{i} g_{j} s_{f i} S_{m j} F_{i j}}
$$

where $g_{k}$ is the genotype frequency, $v_{k}$ is the viability of genotype $k, s_{f i}$ is the sexual selection index for the genotype $i$ female, $s_{m j}$ is the sexual selection index for the genotype $j$ male, $F_{i j}$ is the fecundity of the mating $i \times j$, and the segregation operator, $\mathbf{K}_{i j k}$ is the fraction of progeny of the $i \times j$ mating that are of type $k$ (see table 4). Among the individuals that mate, mating is at random. The populations with $\mathrm{Cy}$ and $\mathrm{Pm}^{2}$ require 5 equations, while populations with $\mathrm{Cy}$ and $\mathrm{Pm}^{1}$ require just 4 (since there is only 1 double heterozygote). The segregation operators for the $\mathrm{Cy} / \mathrm{Pm}^{1}$ populations are 
TABLE 4

Segregation operators. Each element of $\mathrm{K}(\mathrm{ijk})$ indicates the fraction of the progeny of the $\mathrm{i} \times \mathrm{j}$ mating that are of genotype $\mathrm{k}$

$\mathrm{K}_{(\mathrm{Cy})}$

Cy $\quad \mathrm{Pm}^{2} \mathrm{Cy} / \mathrm{Pm}^{2} \mathrm{Cy}-\mathrm{Pm}^{2}$ wild

$\mathrm{K}_{\left(\mathrm{Pm}^{2}\right)}$

$\mathrm{Cy}$
$\mathrm{Pm}{ }^{2}$
$\mathrm{Cy} / \mathrm{Pm}^{2}$
$\mathrm{Cy}-\mathrm{Pm}^{2}$$\quad\left[\begin{array}{ccccc}\frac{2}{3} & \frac{1}{4} & \frac{1}{3} & \frac{1}{3} & \frac{1}{2} \\ \frac{1}{4} & 0 & \frac{1}{3} & 0 & 0 \\ \frac{1}{3} & \frac{1-\mathrm{r}}{3} & \frac{\mathrm{r}}{2} & \frac{1-\mathrm{r}}{2+\mathrm{r}} & \frac{1-\mathrm{r}}{2} \\ \frac{1}{3} & \frac{\mathrm{r}}{3} & \frac{1-\mathrm{r}}{2} & \frac{\mathrm{r}}{3-\mathrm{r}} & \frac{\mathrm{r}}{2} \\ \frac{1}{2} & 0 & \frac{1}{2} & 0 & 0\end{array}\right]\left[\begin{array}{ccccc}0 & \frac{1}{4} & \frac{1}{3} & 0 & 0 \\ \frac{1}{4} & \frac{2}{3} & \frac{1}{3} & \frac{1}{3} & \frac{1}{2} \\ \frac{1-\mathrm{r}}{3} & \frac{1}{3} & \frac{\mathrm{r}}{2} & \frac{1-\mathrm{r}}{2+\mathrm{r}} & \frac{1-\mathrm{r}}{2} \\ \frac{\mathrm{r}}{3} & \frac{1}{3} & \frac{1-\mathrm{r}}{2} & \frac{\mathrm{r}}{3-\mathrm{r}} & \frac{\mathrm{r}}{2} \\ 0 & \frac{1}{2} & \frac{1}{2} & 0 & 0\end{array}\right]$

$\mathrm{K}_{\left(\mathrm{C} y / \mathrm{Pm}^{2}\right)}$

$\mathrm{K}_{\left(\mathrm{C} y-\mathrm{Pm}^{2}\right)}$

$$
\left[\begin{array}{ccccc}
0 & \frac{1}{4} & \frac{1}{3} & 0 & 0 \\
\frac{1}{4} & 0 & \frac{1}{3} & 0 & 0 \\
\frac{1-\mathrm{r}}{3} & \frac{1-\mathrm{r}}{3} & 1-\mathrm{r} & 0 & 0 \\
\frac{\mathrm{r}}{3} & \frac{\mathrm{r}}{3} & \mathrm{r} & 0 & 0 \\
0 & 0 & 0 & 0 & 0
\end{array}\right]\left[\begin{array}{ccccc}
0 & 0 & 0 & \frac{1}{3} & 0 \\
0 & 0 & 0 & \frac{1}{3} & 0 \\
\frac{\mathrm{r}}{3} & \frac{\mathrm{r}}{3} & 0 & \frac{2 \mathrm{r}}{2+\mathrm{r}} & \frac{\mathrm{r}}{2} \\
\frac{1-\mathrm{r}}{3} & \frac{1-\mathrm{r}}{3} & 0 & \frac{2(1-\mathrm{r})}{3-\mathrm{r}} & \frac{1-\mathrm{r}}{2} \\
0 & 0 & 0 & \frac{1}{2} & 0
\end{array}\right]
$$

$\mathrm{K}_{\text {(wild) }}\left[\begin{array}{ccccc}\frac{1}{3} & \frac{1}{4} & 0 & \frac{1}{3} & \frac{1}{2} \\ \frac{1}{4} & \frac{1}{3} & 0 & \frac{1}{3} & \frac{1}{2} \\ \frac{\mathrm{r}}{3} & \frac{\mathrm{r}}{3} & 0 & \frac{\mathrm{r}}{2+\mathrm{r}} & \frac{\mathrm{r}}{2} \\ \frac{1-\mathrm{r}}{3} & \frac{1-\mathrm{r}}{3} & 0 & \frac{1-\mathrm{r}}{3-\mathrm{r}} & \frac{1-\mathrm{r}}{2} \\ \frac{1}{2} & \frac{1}{2} & 0 & \frac{1}{2} & 1\end{array}\right]$

the same as those in table 4, with $r=0$ and the row and column designated $\mathrm{Cy}-\mathrm{Pm}^{2}$ deleted.

Two methods were used to generate families of expected chromosome frequency trajectories based on the estimated fitness components and the initial population composition. The first was a Monte Carlo simulation which generated Gaussian random variables for each fitness component whose mean was the observed mean and whose standard error was $V / N$ 
where $V$ was the observed variance and $N$ was the sample size in the selection experiment. After generating 100 trajectories for each initial condition, the third and ninety-eighth highest frequencies at each generation were plotted. These represented the empirical 96 per cent confidence intervals, and they were compared to the observed trajectories. The second method of verifying the components did not use random fitnesses, but simply allowed sampling error. Given the initial selection population conditions and the fitness estimates, the expected genotype frequencies were determined for the following generation using the above recursion. A multinomial sampling of these genotypes was taken at the adult stage with a sample size equal to that observed in the selection experiment. This procedure was repeated for 10 generations with 100 trajectories for each treatment, and empirical confidence regions were constructed as above.

\section{Results}

\section{(i) Meiotic drive}

A meiotic drive parameter can be assigned to each heterozygote representing the relative frequency of the two alleles that appear in the gametes. In this study there were six kinds of heterozygotes: $\mathrm{Cy} /+, \mathrm{Pm}^{1} /+$, $\mathrm{Pm}^{2} /+, \mathrm{Cy} / \mathrm{Pm}^{1}, \mathrm{Cy} / \mathrm{Pm}^{2}$, and $\mathrm{CyPm}^{2} /++$. As outlined previously, meiotic drive is assessed by analysis of variance of the apparent segregation of the two chromosome types using the three possible crosses as treatments. The standard errors that are reported are not weighted by the sample size of each progeny set because observed variances were 10-30 times as great as the binomial variance. Table 5 summarizes the meiotic drive tests for the heterogeneous background stocks. In the cases of $\mathrm{Cy}$ : wild and $\mathrm{Pm}^{1}$ : wild, the $F$ ratios indicate homogeneity of segregation, so we accept the null hypothesis that there is no meiotic drive operating. It would also appear in these two cases that the segregation ratios are independent of the maternal genotype, so there seems to be no significant maternal or cytoplasmic effect. In the case of $\mathrm{Pm}^{1}$ : wild, however, the null hypothesis is rejected, and we are left with two possibilities. If segregation distortion occurs in $\mathrm{Pm}^{1} /+$, females such that they produce an excess of wild gametes, then the segregation of the wild $\times \mathrm{Pm}^{1}$ crosses would appear to favor the $\mathrm{Pm}^{1}$ genotype. The data are also consistent with a maternal effect operating such that the $\mathrm{Pm}^{1} /+$ genotypes have a higher viability in wild cytoplasm. Although we cannot distinguish the two possibilities, it seems unlikely that meiotic drive is operating, since segregation distortion is generally limited to males in Drosophila (Hartl and Hiraizumi, 1976).

The measurement of meiotic drive in $\mathrm{Cy} / \mathrm{Pm}^{1}, \mathrm{Cy} / \mathrm{Pm}^{2}$, and $\mathrm{Cy}-\mathrm{Pm}^{2}$ genotypes is hindered by the fact that crosses between double heterozygotes do not yield useful information. The $\mathrm{Cy} / \mathrm{Pm}^{1} \times \mathrm{Cy} / \mathrm{Pm}^{1}$ cross for instance yields only $\mathrm{Cy} / \mathrm{Pm}^{1}$ progeny, and the segregation of the progeny in the other crosses is confounded by recombination. We therefore made the reciprocal crosses and did not attempt to separate differences between them into meiotic drive or maternal effects. In the cases of $\mathrm{Cy}: \mathrm{Pm}^{2}$ and $\mathrm{CyPm}{ }^{2}$ : wild (table 5) the reciprocal crosses yield identical segregation ratios, so no drive or maternal effects seem to be present. The $\mathrm{Cy}: \mathrm{Pm}^{1}$ crosses, however are inconsistent, and the direction of the difference indicates a disadvantage for 
TABLE 5

Tests of meiotic drive: heterogeneous background. $\mathrm{k}_{\mathrm{ij}}$ is the segregation ratio of the $\mathrm{i}$ to $\mathrm{j}$ chromosome, and the $\mathrm{F}$ values indicate heterogeneity among them

\begin{tabular}{|c|c|c|c|c|c|}
\hline Chromosomes & Cross & Viais & Flies & $k_{i j}$ & F \\
\hline Cy: wild & $\begin{array}{l}\text { Cy } \times \text { Cy } \\
\text { Cy } \times \text { wild } \\
\text { wild } \times C y\end{array}$ & $\begin{array}{l}93 \\
87 \\
87\end{array}$ & $\begin{array}{l}7480 \\
7797 \\
7376\end{array}$ & $\begin{array}{l}0.824 \pm 0.026 \\
0.885 \pm 0.027 \\
0.891 \pm 0.022\end{array}$ & $1 \cdot 143$ \\
\hline $\mathrm{Pm}^{1}$ : wild & $\begin{array}{l}\mathrm{Pm}^{1} \times \mathrm{Pm}^{1} \\
\mathrm{Pm}^{1} \times \text { wild } \\
\text { wild } \times \mathrm{Pm}^{1}\end{array}$ & $\begin{array}{l}73 \\
82 \\
75\end{array}$ & $\begin{array}{l}2885 \\
5366 \\
4518\end{array}$ & $\begin{array}{l}0.519 \pm 0.029 \\
0.510 \pm 0.022 \\
0.692 \pm 0.024\end{array}$ & $17 \cdot 138^{*}$ \\
\hline $\mathrm{Pm}^{2}$ : wild & $\begin{array}{l}\mathrm{Pm}^{2} \times \mathrm{Pm}^{2} \\
\mathrm{Pm}^{2} \times \text { wild } \\
\text { wild } \times \mathrm{Pm}^{2}\end{array}$ & $\begin{array}{l}94 \\
69 \\
81\end{array}$ & $\begin{array}{l}6489 \\
5416 \\
6855\end{array}$ & $\begin{array}{l}1 \cdot 019 \pm 0.053 \\
0.943 \pm 0.029 \\
1 \cdot 016 \pm 0.032\end{array}$ & 2.632 \\
\hline $\mathrm{Cy}: \mathrm{Pm}^{1}$ & $\begin{array}{l}\mathrm{Cy} / \mathrm{Pm}^{1} \times+ \\
+\times \mathrm{Cy} / \mathrm{Pm}^{1}\end{array}$ & $\begin{array}{l}60 \\
50\end{array}$ & $\begin{array}{l}3488 \\
3313\end{array}$ & $\begin{array}{l}1.555 \pm 0.095 \\
2.023 \pm 0.140\end{array}$ & $11.459^{*}$ \\
\hline $\mathrm{Cy}: \mathrm{Pm}^{2}$ & $\begin{array}{l}\mathrm{Cy} / \mathrm{Pm}^{2} \times+ \\
+\times \mathrm{Cy} / \mathrm{Pm}^{2}\end{array}$ & $\begin{array}{l}54 \\
48\end{array}$ & $\begin{array}{l}3886 \\
2256\end{array}$ & $\begin{array}{l}0.812 \pm 0.037 \\
0.878 \pm 0.038\end{array}$ & $1 \cdot 418$ \\
\hline $\mathrm{CyPm}^{2}$ : wild & $\begin{array}{l}\text { Cy }-\mathrm{Pm}^{2} x+ \\
+\times \text { Cy }-\mathrm{Pm}^{2}\end{array}$ & $\begin{array}{l}55 \\
47\end{array}$ & $\begin{array}{l}3038 \\
4553\end{array}$ & $\begin{array}{l}0.908 \pm 0.056 \\
0.958 \pm 0.028\end{array}$ & $1 \cdot 311$ \\
\hline
\end{tabular}

$\mathrm{Pm}^{1}$ gametes from males, or a disadvantage for the $\mathrm{Pm}^{1} /+$ genotype in the wild cytoplasm. Note that the latter possibility is not consistent with the observation of the $\mathrm{Pm}^{1}$ : wild maternal effect.

Table 6 summarizes these six tests for meiotic drive and maternal effects in stocks with homogeneous background. In all of these cases the $F$ values fall below the 5 per cent critical values, so the crosses appear to be homogeneous. There is, therefore, no evidence for meiotic drive or maternal effects in these experiments.

\section{(ii) Viability}

The relative viability of two genotypes was measured by dividing their frequencies within progeny sets by the expected Mendelian proportions. As

TABLE 6

Tests of meiotic drive: homogeneous background

\begin{tabular}{|c|c|c|c|c|c|}
\hline Chromosomes & Cross & Vials & Flies & $k_{i j}$ & $\mathrm{~F}$ \\
\hline Cy: wild & $\begin{array}{l}\mathrm{Cy} \times \mathrm{Cy} \\
\mathrm{Cy} \times \text { wild } \\
\text { wild } \times \mathrm{Cy}\end{array}$ & $\begin{array}{l}164 \\
137 \\
113\end{array}$ & $\begin{array}{r}14335 \\
10042 \\
7691\end{array}$ & $\begin{array}{l}0.883 \pm 0.018 \\
0.935 \pm 0.021 \\
0.889 \pm 0.028\end{array}$ & $1 \cdot 120$ \\
\hline $\mathrm{Pm}^{1}$ : wild & $\begin{array}{l}\mathrm{Pm}^{1} \times \mathrm{Pm}^{1} \\
\mathrm{Pm}^{1} \times \text { wild } \\
\text { wild } \times \mathrm{Pm}^{1}\end{array}$ & $\begin{array}{l}90 \\
80 \\
83\end{array}$ & $\begin{array}{l}4328 \\
4101 \\
6654\end{array}$ & $\begin{array}{l}0.618 \pm 0.043 \\
0.576 \pm 0.067 \\
0.601 \pm 0.031\end{array}$ & 0.925 \\
\hline $\mathrm{Pm}^{2}$ : wild & $\begin{array}{l}\mathrm{Pm}^{2} \times \mathrm{Pm}^{2} \\
\mathrm{Pm}^{2} \times \text { wild } \\
\text { wild } \times \mathrm{Pm}^{2}\end{array}$ & $\begin{array}{r}159 \\
99 \\
92\end{array}$ & $\begin{array}{r}12863 \\
7074 \\
7906\end{array}$ & $\begin{array}{l}0.911 \pm 0.028 \\
0.908 \pm 0.032 \\
0.984 \pm 0.022\end{array}$ & 1.079 \\
\hline $\mathrm{Cy}: \mathrm{Pm}^{1}$ & $\begin{array}{l}\mathrm{Cy} / \mathrm{Pm}^{1} \times+ \\
+\times \mathrm{Cy} / \mathrm{Pm}^{1}\end{array}$ & $\begin{array}{l}75 \\
76\end{array}$ & $\begin{array}{l}3544 \\
3507\end{array}$ & $\begin{array}{l}1.478 \pm 0.113 \\
1.516 \pm 0.099\end{array}$ & 0.014 \\
\hline $\mathrm{Cy}: \mathrm{Pm}^{2}$ & $\begin{array}{l}\mathrm{Cy} / \mathrm{Pm}^{2} x+ \\
+\times \mathrm{Cy} / \mathrm{Pm}^{2}\end{array}$ & $\begin{array}{r}70 \\
121\end{array}$ & $\begin{array}{l}3315 \\
6385\end{array}$ & $\begin{array}{l}0.857 \pm 0.044 \\
0.901 \pm 0.034\end{array}$ & 0.401 \\
\hline CyPm${ }^{2}$ : wild & $\begin{array}{l}\mathrm{Cy}-\mathrm{Pm}^{2} \times+ \\
+\times \mathrm{Cy}-\mathrm{Pm}^{2}\end{array}$ & $\begin{array}{l}64 \\
55\end{array}$ & $\begin{array}{l}4743 \\
3803\end{array}$ & $\begin{array}{l}0.918 \pm 0.035 \\
0.876 \pm 0.033\end{array}$ & 0.888 \\
\hline
\end{tabular}




\section{TABLE 7}

Viability sex dependence: heterogeneous background. F values indicate significance of differences between female and male viabilities

\begin{tabular}{|c|c|c|c|c|c|}
\hline \multirow[b]{2}{*}{ Genotypes } & \multicolumn{4}{|c|}{ Heterogeneous background } & \multirow[b]{2}{*}{$F$} \\
\hline & Sex & Vials & Flies & Viability & \\
\hline Cy: wild & $\begin{array}{c}\text { female } \\
\text { male }\end{array}$ & $\begin{array}{l}120 \\
120\end{array}$ & $\begin{array}{l}6422 \\
6375\end{array}$ & $\begin{array}{l}0.919 \pm 0.027 \\
0.841 \pm 0.023\end{array}$ & $5 \cdot 821^{*}$ \\
\hline $\mathrm{Pm}^{1}$ : wild & $\begin{array}{c}\text { female } \\
\text { male }\end{array}$ & $\begin{array}{l}136 \\
136\end{array}$ & $\begin{array}{l}4166 \\
4269\end{array}$ & $\begin{array}{l}0.606 \pm 0.025 \\
0.528 \pm 0.027\end{array}$ & $4 \cdot 11^{*}$ \\
\hline $\mathrm{Pm}^{2}:$ wild & $\begin{array}{c}\text { female } \\
\text { male }\end{array}$ & $\begin{array}{l}131 \\
131\end{array}$ & $\begin{array}{l}5641 \\
5946\end{array}$ & $\begin{array}{l}0.976 \pm 0.034 \\
1.032 \pm 0.047\end{array}$ & $2 \cdot 341^{*}$ \\
\hline $\mathrm{Cy} / \mathrm{Pm}^{1}:$ wild & $\begin{array}{c}\text { female } \\
\text { male }\end{array}$ & $\begin{array}{l}20 \\
20\end{array}$ & $\begin{array}{l}332 \\
335\end{array}$ & $\begin{array}{l}0.612 \pm 0.149 \\
0.450 \pm 0.079\end{array}$ & $1 \cdot 544$ \\
\hline $\mathrm{Cy} / \mathrm{Pm}^{2}$ : wild & $\begin{array}{c}\text { female } \\
\text { male }\end{array}$ & $\begin{array}{l}30 \\
30\end{array}$ & $\begin{array}{l}673 \\
666\end{array}$ & $\begin{array}{l}0.901 \pm 0.077 \\
0.809 \pm 0.064\end{array}$ & $1 \cdot 029$ \\
\hline $\mathrm{Cy}-\mathrm{Pm}^{2}$ : wild & $\begin{array}{c}\text { female } \\
\text { male }\end{array}$ & $\begin{array}{l}27 \\
27\end{array}$ & $\begin{array}{l}573 \\
662\end{array}$ & $\begin{array}{l}0.964 \pm 0.098 \\
0.902 \pm 0.084\end{array}$ & $0 \cdot 010$ \\
\hline
\end{tabular}

table 1 indicates, there are a number of crosses which yield information about the relative viability of pairs of genotypes. If the only phenomenon causing differences in segregation were constant viability differences, then the viability estimates obtained by these different crosses would be homogeneous. Before the tests of homogeneity of viability estimates were performed, a priori comparisons were done to ascertain the importance of several factors on viability. These included sex, larval competition and density.

Tables 7 and 8 record the results of tests to distinguish viability differences between the sexes. Estimates of viability were significantly higher for females than males in the comparisons of $\mathrm{Cy}$ : wild and $\mathrm{Pm}^{1}$ : wild with heterogeneous background. In the homogeneous stocks, no differences in viability were found between the sexes.

An attempt to measure competitive larval interactions in viability was made by comparing the relative viability of a pair of genotypes in progeny

TABLE 8

Viability sex dependence: homogeneous background

\begin{tabular}{|c|c|c|c|c|c|}
\hline \multicolumn{6}{|c|}{ Homogeneous background } \\
\hline Genotypes & Sex & Vials & Flies & Viability & $\mathrm{F}$ \\
\hline Cy: wild & $\begin{array}{c}\text { female } \\
\text { male }\end{array}$ & $\begin{array}{l}266 \\
266\end{array}$ & $\begin{array}{l}6527 \\
6595\end{array}$ & $\begin{array}{l}0.999 \pm 0.038 \\
0.925 \pm 0.029\end{array}$ & $3 \cdot 782$ \\
\hline $\mathrm{Pm}^{1}$ : wild & $\begin{array}{c}\text { female } \\
\text { male }\end{array}$ & $\begin{array}{l}272 \\
272\end{array}$ & $\begin{array}{l}4722 \\
5015\end{array}$ & $\begin{array}{l}0.594 \pm 0.031 \\
0.629 \pm 0.034\end{array}$ & 0.417 \\
\hline $\mathrm{Pm}^{2}$ : wild & $\begin{array}{c}\text { female } \\
\text { male }\end{array}$ & $\begin{array}{l}290 \\
290\end{array}$ & $\begin{array}{l}6417 \\
6705\end{array}$ & $\begin{array}{l}0.888 \pm 0.029 \\
0.955 \pm 0.031\end{array}$ & $3 \cdot 276$ \\
\hline $\mathrm{Cy} / \mathrm{Pm}^{1}$ : wild & $\begin{array}{c}\text { female } \\
\text { male }\end{array}$ & $\begin{array}{l}82 \\
82\end{array}$ & $\begin{array}{l}840 \\
850\end{array}$ & $\begin{array}{l}0.450 \pm 0 \cdot 043 \\
0.482 \pm 0 \cdot 046\end{array}$ & 0.486 \\
\hline $\mathrm{Cy} / \mathrm{Pm}^{2}$ : wild & $\begin{array}{c}\text { female } \\
\text { male }\end{array}$ & $\begin{array}{l}49 \\
49\end{array}$ & $\begin{array}{l}1152 \\
1098\end{array}$ & $\begin{array}{l}0.748 \pm 0 \cdot 048 \\
0.841 \pm 0 \cdot 062\end{array}$ & $2 \cdot 642$ \\
\hline Cy-Pm ${ }^{2}$ : wild & $\begin{array}{c}\text { female } \\
\text { male }\end{array}$ & $\begin{array}{l}47 \\
47\end{array}$ & $\begin{array}{r}1062 \\
988\end{array}$ & $\begin{array}{l}0.822 \pm 0 \cdot 044 \\
0.892 \pm 0.065\end{array}$ & 1.981 \\
\hline
\end{tabular}


sets containing only those two genotypes to the relative viability of the same two genotypes when other larval genotypes were present. For example, if the cross $\mathrm{Cy} \times$ wild produced $m_{1} \mathrm{Cy}$ and $m_{2}$ wild progeny, the viability estimate of $\mathrm{Cy}$ is $m_{1} / m_{2}$. If the cross $\mathrm{Cy} \times \mathrm{Pm}^{2}$ produced $n_{1} \mathrm{Cy}, n_{2} \mathrm{Pm}^{2}, n_{3}$ $\mathrm{Cy} / \mathrm{Pm}^{2}$, and $n_{4}$ wild progeny, the estimate of $\mathrm{Cy}$ viability relative to wild type is $n_{1} / n_{4}$, which may be different from $m_{1}^{-} / m_{2}$ if the presence of $\mathrm{Pm}^{2}$ or $\mathrm{Cy} / \mathrm{Pm}^{2}$ larvae alter the survivorship of $\mathrm{Cy}$. If we assume that viabilities are density independent, then if $\left(m_{1} / m_{2}\right) \neq\left(n_{1} / n_{4}\right)$ we can infer that there are larval interactions. Table 9 reports the significance of tests in which the wild

TABLE 9

Significance of larval competition on viability

$\begin{array}{lcc}\text { Genotypes } & \begin{array}{c}\text { Heterogeneous } \\ \text { background }\end{array} & \begin{array}{c}\text { Homogeneous } \\ \text { background }\end{array} \\ \mathrm{Cy}: \text { wild } & - & - \\ \mathrm{Pm}^{1} \text { : wild } & - & - \\ \mathrm{Pm}^{2}: \text { wild } & - & * \\ \mathrm{Cy} / \mathrm{Pm}^{1} \text { : wild } & - & - \\ \mathrm{Cy} / \mathrm{Pm}^{2} \text { : wild } & - & - \\ \mathrm{Cy}-\mathrm{Pm}^{2} \text { : wild } & * & -\end{array}$

type was one of the genotypes being compared. In general the larval interactions do not seem to play an important role, although, in two of the cases the effect exceeded the 5 per cent level of significance.

The effect of density on viability was assessed by performing linear regressions of viability on density for the various pairs of genotypes raised in vials. In these regressions, each vial was a single point, since it represented one observation of relative viability and an associated progeny density. A total of 12 regressions were performed, representing tests of the six genotypic viabilities relative to wild type with two genetic backgrounds. Sample sizes for each test were of the order of 100 vials and 6000 flies, with densities ranging from 20 to 160 flies per vial. In no case was there a significant effect of density on viability. Had there been significant density dependence, the estimates of viability and fecundity components would have been confounded.

Since population prediction required estimates of components in half pint bottles, viability estimates obtained by segregation ratios in vials were compared to the viabilities in the bottle environment. This was done for all genotypes relative to wild type by mating 20,4 -day-old virgin females to wild males and allowing them to lay eggs in half pint bottles with Carolina 4-24 instant medium for 4 days. On the 18 th day the relative viabilities were assessed as outlined above. Four replicates of each viability test were done, and in no case was the relative viability in the bottle environment different from the viability in vials.

By observing the segregation ratio of flies emerging from bottles each day, and among cumulative survivors, age dependence of viabilities was assessed. A representative graph of these data is presented in fig. 1. It appears that among flies emerging in the time interval from 10-18 days post-egglaying the relative viabilities are independent of age. 


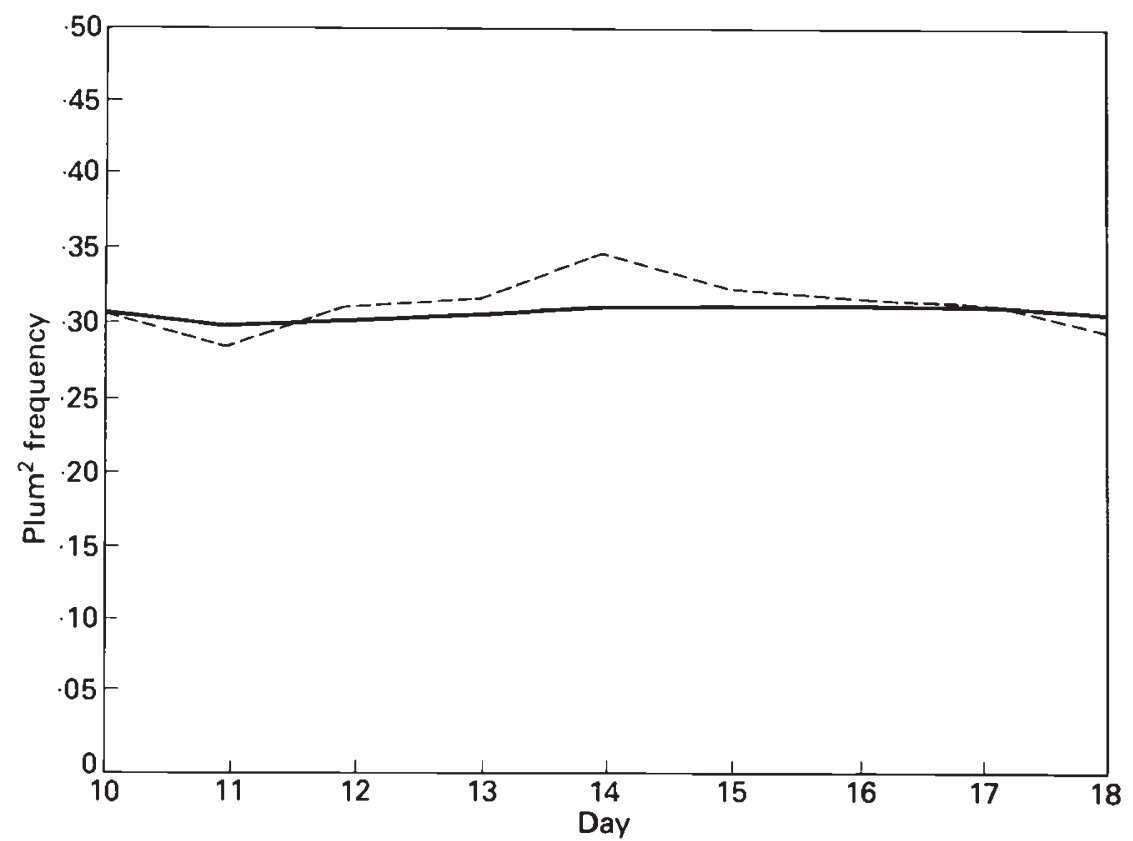

FIG. 1.-Age independence of viability. Dashed line represents segregation among progeny harvested each day; solid line represents cumulative segregation ratio.

The pooled viability estimates are listed with the respective sample sizes and standard errors in tables 10 and 11 and fig. 2. By taking ratios of various viabilities we can check the internal consistency of these tables. For each background there are 11 internal checks as outlined in table 12. An example

\section{TABLE 10}

Viability: heterogeneous background. Each entry gives the viability of the genotype heading the row relative to the genotype heading the column +1 standard error. Numbers in parentheses indicate number of progeny sets and total sample size

\begin{tabular}{|c|c|c|c|c|}
\hline & $\mathrm{Pm}^{1}$ & \multicolumn{2}{|c|}{$\mathrm{Cy} / \mathrm{Pm}^{1}$} & wild \\
\hline $\mathrm{Cy}$ & \multirow[t]{2}{*}{$\begin{array}{c}1 \cdot 564 \pm 0 \cdot 067 \\
(248,11602)\end{array}$} & \multicolumn{2}{|c|}{$\begin{array}{c}1 \cdot 527 \pm 0 \cdot 123 \\
(138,4531)\end{array}$} & $\left.\begin{array}{c}0 \cdot 855 \pm 0 \cdot 013 \\
(391,31475)\end{array}\right]$ \\
\hline $\mathrm{Pm}^{1}$ & & \multicolumn{2}{|c|}{$\begin{array}{c}1 \cdot 150 \pm 0 \cdot 062 \\
(138,3856)\end{array}$} & $\begin{array}{c}0 \cdot 610 \pm 0 \cdot 015 \\
(286,16054)\end{array}$ \\
\hline \multirow[t]{2}{*}{$\mathrm{Cy} / \mathrm{Pm}^{1}$} & ᄂ & & & $\begin{array}{c}0 \cdot 474 \pm 0 \cdot 055 \\
(37,985)\end{array}$ \\
\hline & $\mathrm{Pm}^{2}$ & $\mathrm{Cy} / \mathrm{Pm}^{2}$ & $\mathrm{Cy}-\mathrm{Pm}^{2}$ & wild \\
\hline $\mathrm{Cy}$ & {$\left[\begin{array}{c}0.894 \pm 0.024 \\
(352,15136)\end{array}\right.$} & $\begin{array}{c}0 \cdot 915 \pm 0 \cdot 103 \\
(83,3601)\end{array}$ & $\begin{array}{c}0 \cdot 867 \pm 0 \cdot 152 \\
(12,857)\end{array}$ & $\begin{array}{c}0.855 \pm 0.013 \\
(391,31475)\end{array}$ \\
\hline $\mathrm{Pm}^{2}$ & & $\begin{array}{c}1 \cdot 049 \pm 0 \cdot 053 \\
(83,3852)\end{array}$ & $\begin{array}{c}0 \cdot 976 \pm 0 \cdot 070 \\
(13,832)\end{array}$ & $\begin{array}{c}0.968 \pm 0 \cdot 020 \\
(329,25138)\end{array}$ \\
\hline $\mathrm{Cy} / \mathrm{Pm}^{2}$ & & & & $\begin{array}{c}0 \cdot 900 \pm 0 \cdot 054 \\
(42,1911)\end{array}$ \\
\hline Cy-Pm ${ }^{2}$ & L & & & $\begin{array}{c}0.950 \pm 0.021 \\
(264,15683)\end{array}$ \\
\hline
\end{tabular}



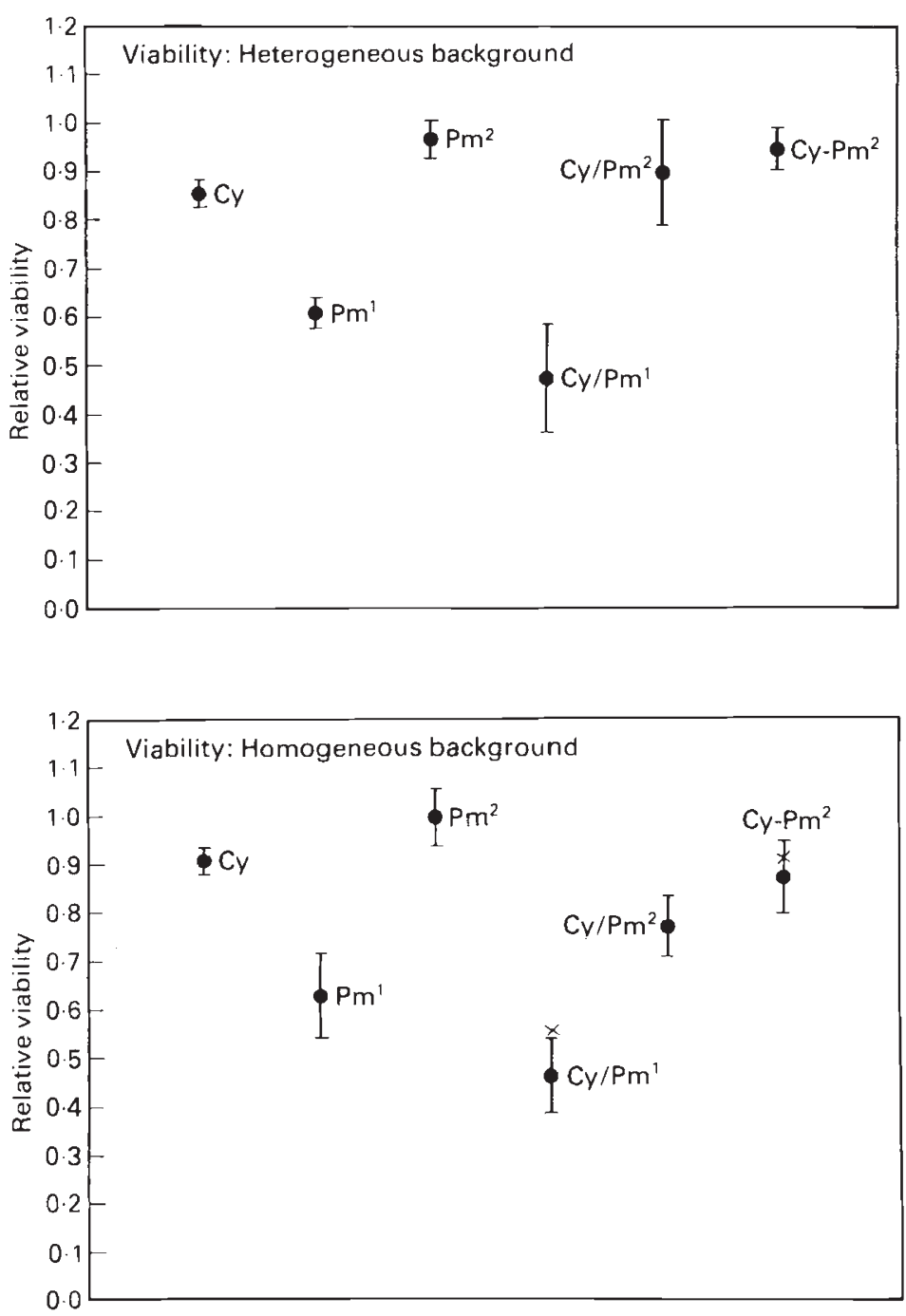

FIG. 2.-Pooled viabilities relative to wild type: heterogeneous background above, homogeneous background below. Means and 95 per cent confidence intervals are plotted.

of such a check is the $\mathrm{Cy}: \mathrm{Pm}^{2}$ relative viability which is not significantly different from the ratio of $\mathrm{Cy}$ : wild to $\mathrm{Pm}^{2}$ : wild viabilities. Significance tests for the equivalence of these ratios were performed, and 19 out of 22 of the internal checks were consistent. Fig. 3 illustrates the viability relations graphically.

Indices of multiplicative and additive epistasis in viability are tabulated in table 13 along with their approximate 95 per cent confidence intervals, and suggest that epistasis is an important aspect of viability selection. The viability tables indicate a viability advantage for $\mathrm{CyPm} /++$ over $\mathrm{Cy} / \mathrm{Pm}^{2}$ double heterozygotes in the homogeneous background, and this cis-trans 
TABLE 11

Viability: homogeneous background

\begin{tabular}{|c|c|c|c|c|}
\hline & $\mathrm{Pm}^{1}$ & \multicolumn{2}{|c|}{$\mathrm{Cy} / \mathrm{Pm}^{1}$} & wild \\
\hline Cy & \multirow[t]{2}{*}{$\begin{array}{c}1.497 \pm 0 \cdot 075 \\
(151,7051)\end{array}$} & \multicolumn{2}{|c|}{$\begin{array}{c}1 \cdot 845 \pm 0 \cdot 115 \\
(126,4740)\end{array}$} & $\left.\begin{array}{c}0 \cdot 908 \pm 0 \cdot 013 \\
(440,33008)\end{array}\right]$ \\
\hline $\mathrm{Pm}^{1}$ & & \multicolumn{2}{|c|}{$\begin{array}{c}1 \cdot 170 \pm 0 \cdot 063 \\
(118,3511)\end{array}$} & $\begin{array}{c}0.628 \pm 0 \cdot 043 \\
(176,7331)\end{array}$ \\
\hline $\mathrm{Cy} / \mathrm{Pm}^{1}$ & $\leftarrow$ & & & $\left.\begin{array}{c}0.464 \pm 0.039 \\
(59,2356)\end{array}\right]$ \\
\hline & $\mathrm{Pm}^{2}$ & $\mathrm{Cy} / \mathrm{Pm}^{2}$ & $\mathrm{Cy}-\mathrm{Pm}^{2}$ & wild \\
\hline Cy & {$\left[\begin{array}{c}0 \cdot 913 \pm 0 \cdot 021 \\
(309,14502)\end{array}\right.$} & $\begin{array}{c}1 \cdot 186 \pm 0 \cdot 053 \\
(102,4680)\end{array}$ & $\begin{array}{c}0.948 \pm 0.039 \\
(63,3784)\end{array}$ & $\begin{array}{c}0 \cdot 908 \pm 0 \cdot 013 \\
(440,33008)\end{array}$ \\
\hline $\mathrm{Pm}^{2}$ & & $\begin{array}{c}1 \cdot 306 \pm 0 \cdot 047 \\
(102,4938)\end{array}$ & $\begin{array}{c}1 \cdot 039 \pm 0 \cdot 070 \\
(14,995)\end{array}$ & $\begin{array}{c}0.998 \pm 0 \cdot 029 \\
(270,16312)\end{array}$ \\
\hline $\mathrm{Cy} / \mathrm{Pm}^{2}$ & & & & $\begin{array}{c}0 \cdot 774 \pm 0 \cdot 031 \\
(100,4968)\end{array}$ \\
\hline $\mathrm{Cy}-\mathrm{Pm}^{2}$ & & & & $\begin{array}{c}0 \cdot 875 \pm 0 \cdot 038 \\
(132,9298)\end{array}$ \\
\hline
\end{tabular}

TABLE 12

Tests of consistency of viability measures. Each viability comparison in column $A$ is expected to equal the ratio of viabilities indicated in column $B$

Viability comparison (A) Equivalent ratio

$$
\begin{array}{ll}
\mathrm{Cy}: \mathrm{Pm}^{1} & \mathrm{Cy}:+/ \mathrm{Pm}^{1}:+ \\
& \mathrm{Cy}: \mathrm{Cy} / \mathrm{Pm}^{1} / \mathrm{Pm}^{1}: \mathrm{Cy} / \mathrm{Pm}^{1} \\
& \mathrm{Cy}: \mathrm{Cy} / \mathrm{Pm}^{1}{ }^{1} \mathrm{Cy}:+/ \mathrm{Cy} / \mathrm{Pm}^{1}:+ \\
\mathrm{Pm}^{1}: \mathrm{Cy} / \mathrm{Pm}^{1} \mathrm{Pm}^{1}:+/ \mathrm{Cy} / \mathrm{Pm}^{1}:+ \\
\mathrm{Cy}: \mathrm{Pm}^{2} & \mathrm{Cy}:+/ \mathrm{Pm}^{2}:+ \\
& \mathrm{Cy}: \mathrm{Cy} / \mathrm{Pm}^{2} / \mathrm{Pm}^{2}: \mathrm{Cy} / \mathrm{Pm}^{2} \\
& \mathrm{Cy}: \mathrm{Cy}-\mathrm{Pm}^{2} / \mathrm{Pm}^{2}: \mathrm{Cy}-\mathrm{Pm}^{2}
\end{array}
$$

$\mathrm{Cy}: \mathrm{Cy} / \mathrm{Pm}^{2} \mathrm{Cy}:+/ \mathrm{Cy} / \mathrm{Pm}^{2}:+$

$\mathrm{Cy}: \mathrm{Cy}-\mathrm{Pm}^{2} \mathrm{Cy}:+/ \mathrm{Cy}-\mathrm{Pm}^{2}:+$ $\mathrm{Pm}^{2}: \mathrm{Cy} / \mathrm{Pm}^{2} \mathrm{Pm}^{2}:+/ \mathrm{Cy} / \mathrm{Pm}^{2}:+$ $\mathrm{Pm}^{2}: \mathrm{Cy}-\mathrm{Pm}^{2} \mathrm{Pm}^{2}:+/ \mathrm{Cy}-\mathrm{Pm}^{2}:+$

\section{Heterogeneous background}

A B

A

\section{Homogeneous} background B

$\begin{array}{llll}1.56 \pm 0.07 & 1.40 \pm 0.08 & 1.50 \pm 0.08 & 1.45 \pm 0.06 \\ & 1.33 \pm 0.09^{*} & & 1.58 \pm 0.09 \\ 1.53 \pm 0.12 & 1.80 \pm 0.07 * & 1.84 \pm 0.12 & 1.94 \pm 0.07 \\ 1.15 \pm 0.06 & 1.29 \pm 0.06^{*} & 1.17 \pm 0.06 & 1.35 \pm 0.09 \\ 0.89 \pm 0.02 & 0.88 \pm 0.02 & 0.91 \pm 0.02 & 0.91 \pm 0.02 \\ & 0.87 \pm 0.08 & & 0.91 \pm 0.04 \\ & 0.89 \pm 0.12 & & 0.91 \pm 0.04 \\ 0.92 \pm 0.10 & 0.95 \pm 0.02 & 1.19 \pm 0.05 & 1.17 \pm 0.02 \\ 0.87 \pm 0.15 & 0.90 \pm 0.02 & 0.95 \pm 0.04 & 1.04 \pm 0.03 \\ 1.05 \pm 0.05 & 1.08 \pm 0.03 & 1.31 \pm 0.05 & 1.29 \pm 0.04 \\ 0.98 \pm 0.07 & 1.02 \pm 0.02 & 1.04 \pm 0.07 & 1.14 \pm 0.04\end{array}$

TABLE 13

Viability epistasis and confidence intervals

Heterogeneous background

$$
\begin{aligned}
& \mathrm{Cy} / \mathrm{Pm}^{1} \\
& \mathrm{Cy} / \mathrm{Pm}^{2} \\
& \mathrm{Cy}-\mathrm{Pm}^{2}
\end{aligned}
$$

Homogeneous background

$$
\begin{aligned}
& \mathrm{Cy} / \mathrm{Pm}^{1} \\
& \mathrm{Cy} / \mathrm{Pm}^{2} \\
& \mathrm{Cy}-\mathrm{Pm}^{2}
\end{aligned}
$$

\begin{tabular}{cc}
\multicolumn{1}{c}{ Additive } & \multicolumn{1}{c}{ Multiplicative } \\
$0.009 \pm 0.114$ & $-0.096 \pm 0.082^{*}$ \\
$0.077 \pm 0.063^{*}$ & $0.084 \pm 0.047^{*}$ \\
$0.127 \pm 0.116^{*}$ & $0.138 \pm 0.084^{*}$
\end{tabular}

Additive Multiplicative

$$
\begin{array}{ll}
-0.072 \pm 0.116 & -0.206 \pm 0.043^{*} \\
-0.132 \pm 0.086^{*} & -0.158 \pm 0.031^{*} \\
-0.031 \pm 0.096 & -0.034 \pm 0.029^{*}
\end{array}
$$



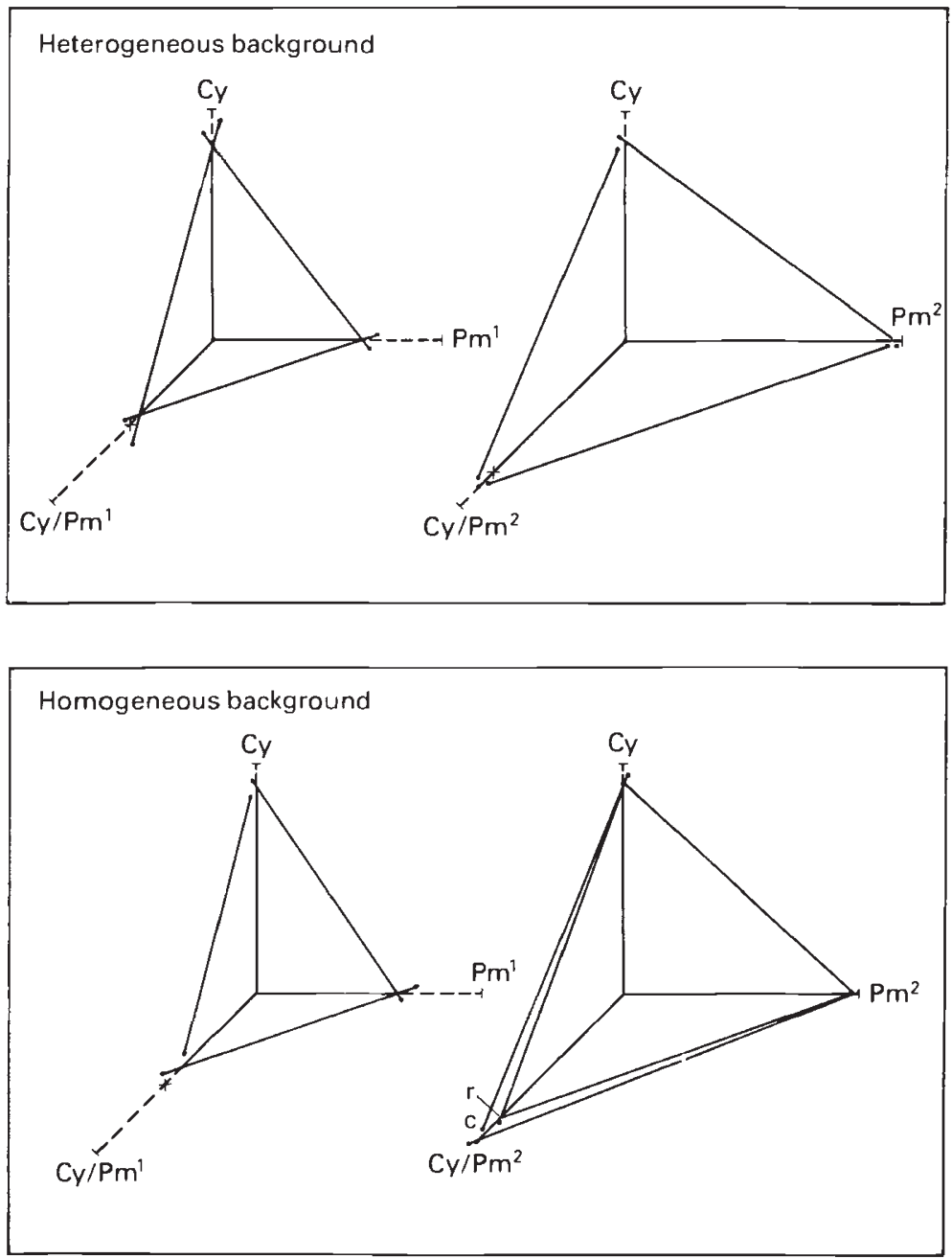

FIG. 3.-Consistency of viability measures in both backgrounds. Lengths indicate $\mathrm{Cy}, \mathrm{Pm}$, and CyPm viabilities relative to wild type. Diagonal lines indicate the relative viabilities of the 2 mutant types determined by independent tests, scaled in such a way that a fit to the two viability endpoints would indicate equivalence of quantities A and B defined in table 12 . $x$ indicates points of zero multiplicative epistasis in all figures.

effect in viability necessitates the calculation of an epistatic parameter for each double heterozygote. As a result, there is significant negative epistasis in the cis phase, but no epistasis in the trans phase. The background effect resulted in a reversal of epistasis in the $\mathrm{Cy} / \mathrm{Pm}^{2}$ tests, suggesting a higher order interaction between genes on the inversions and the rest of the genome.

\section{(iii) Fecundity}

From each experiment outlined in the description of the general paradigm we obtain distributions of productivity of four mating types (e.g., 
TABLE 14

Fecundities: heterogeneous background. Each entry indicates the mean \pm 1 standard error of the number of progeny produced per mating scored on day 18. Numbers in parentheses indicate number of matings and total progeny sample size

Female

Cy

\begin{tabular}{|c|c|}
\hline $\mathrm{Cy}$ & $\begin{array}{l}80 \cdot 83 \pm 2 \cdot 92 \\
(144,11640)\end{array}$ \\
\hline $\mathrm{Pm}^{1}$ & $\begin{array}{c}49 \cdot 04 \pm 3 \cdot 61 \\
(21,1030)\end{array}$ \\
\hline $\mathrm{Cy} / \mathrm{Pm}^{1}$ & $\begin{array}{c}57 \cdot 40 \pm 5 \cdot 16 \\
(20,1148)\end{array}$ \\
\hline fild & $\begin{array}{c}123 \cdot 78 \pm 7 \cdot 03 \\
-\quad(18,2228)\end{array}$ \\
\hline
\end{tabular}

Female

Cy

\begin{tabular}{l|c}
$\mathrm{Cy}$ & $80 \cdot 83 \pm 2 \cdot 92$ \\
& $(144,1,640)$ \\
$\mathrm{Pm}^{2}$ & $78 \cdot 94 \pm 7 \cdot 20$ \\
& $(16,1263)$ \\
$\mathrm{Cy} / \mathrm{Pm}^{2}$ & $83 \cdot 94 \pm 6 \cdot 47$ \\
& $(19,1595)$ \\
$\mathrm{Cy}-\mathrm{Pm}^{2}$ & $85 \cdot 10 \pm 6 \cdot 59$ \\
& $(19,1617)$ \\
wild & $123 \cdot 78 \pm 11 \cdot 03$ \\
$(18,2228)$
\end{tabular}

Male

$\left.\begin{array}{ccc}\mathrm{Pm}^{1} & \mathrm{Cy} / \mathrm{Pm}^{1} & \text { wild } \\ 57 \cdot 31 \pm 6 \cdot 20 & 53 \cdot 8 \pm 9 \cdot 02 & 85 \cdot 83 \pm 10 \cdot 84 \\ (16,917) & (15,807) & (12,1030) \\ 55 \cdot 01 \pm 2 \cdot 31 & 57 \cdot 15 \pm 3 \cdot 82 & 56 \cdot 00 \pm 4 \cdot 58 \\ (85,4676) & (34,1943) & (14,784) \\ 44 \cdot 28 \pm 4 \cdot 28 & 36 \cdot 63 \pm 1 \cdot 87 & 62 \cdot 88 \pm 3 \cdot 78 \\ (32,1417) & (83,3040) & (25,1572) \\ 80 \cdot 64 \pm 3 \cdot 48 & 86 \cdot 65 \pm 6 \cdot 97 & 109 \cdot 50 \pm 3 \cdot 38 \\ (28,2258) & (17,1473) & (125,13687)\end{array}\right]$

Male

$\left.\begin{array}{cccc}\mathrm{Pm}^{2} & \mathrm{Cy} / \mathrm{Pm}^{2} & \mathrm{Cy}-\mathrm{Pm}^{2} & \text { wild } \\ 92 \cdot 92 \pm 7 \cdot 34 & 81 \cdot 73 \pm 7 \cdot 28 & 102 \cdot 26 \pm 7 \cdot 27 & 85 \cdot 83 \pm 10 \cdot 84 \\ (26,2417) & (22,1798) & (27,2761) & (12,1030) \\ 73 \cdot 61 \pm 2 \cdot 55 & 70 \cdot 47 \pm 5 \cdot 25 & 97 \cdot 23 \pm 7 \cdot 45 & 88 \cdot 70 \pm 7 \cdot 36 \\ (122,8980) & (32,2255) & (13,1264) & (10,887) \\ 71 \cdot 96 \pm 5 \cdot 39 & 61 \cdot 00 \pm 2 \cdot 57 & 69 \cdot 83 \pm 5 \cdot 33 & 102 \cdot 05 \pm 7 \cdot 95 \\ (27,1943) & (84,5124) & (23,1606) & (20,2041) \\ 56 \cdot 06 \pm 5 \cdot 70 & 57 \cdot 74 \pm 3 \cdot 59 & 66 \cdot 17 \pm 3 \cdot 20 & 84 \cdot 81 \pm 6 \cdot 70 \\ (16,897) & (19,1097) & (77,5095) & (26,2205) \\ 92 \cdot 60 \pm 8 \cdot 47 & 79 \cdot 43 \pm 7 \cdot 82 & 127 \cdot 56 \pm 7 \cdot 08 & 109 \cdot 50 \pm 3 \cdot 38 \\ (10,926) & (21,1668) & (16,2041) & (125,13687)\end{array}\right]$

$\mathrm{Cy} \times \mathrm{Cy}, \mathrm{Cy} \times$ wild, wild $\times \mathrm{Cy}$, and wild $\times$ wild). Two-way analysis of variance was performed on these data to ascertain relative importance of the female's genotype, the male's genotype, and female $\times$ male interactions in the determination of fecundity. Out of 25 two way tests done on the data from heterogeneous background stocks, 21 had significant female effects, 7 had significant male effects, and 2 showed significant interactions. The homogeneous background data revealed 21 cases of significant female effects, 7 with significant male effects and 3 significant interactions out of 25 tests.

The pooled fecundity data for each genetic background are presented in tables 14 and 15 . We report the mean number of progeny scored on day 18 , the standard error and sample size for each mating type. These tables are in the format of table 2 except that the tables with the $\mathrm{Pm}^{2}$ allele have an additional row and column due to the existence of two double heterozygotes. The sample sizes vary between mating types because mating probabilities differ, and some crosses were performed more frequently to obtain viability estimates. The female and male fecundity parameters defined in table 2 were estimated numerically by the method of maximum likelihood, and standard errors of these estimates were determined in the usual way from derivatives of the likelihood. Both the additive and multiplicative fecundity models adequately fitted the fecundity data as shown in table 16 . Fig. 4 represents the multiplicative fecundity parameters for both sexes. The 
TABLE 15

Fecundities: homogeneous background

Female

\begin{tabular}{|c|c|}
\hline & Cy \\
\hline Cy & {$\left[\begin{array}{l}89 \cdot 87 \pm 2 \cdot 31 \\
(185,16627)\end{array}\right.$} \\
\hline $\mathrm{Pm}^{1}$ & $\begin{array}{c}58 \cdot 91 \pm 3 \cdot 16 \\
(32,1885)\end{array}$ \\
\hline $\mathrm{Cy} / \mathrm{Pm}^{1}$ & $\begin{array}{c}50 \cdot 13 \pm 4 \cdot 17 \\
(23,1153)\end{array}$ \\
\hline wild & {$\left[\begin{array}{c}114 \cdot 19 \pm 8 \cdot 00 \\
(21,2398)\end{array}\right.$} \\
\hline
\end{tabular}

Female

$$
\begin{gathered}
\mathrm{Pm}^{1} \\
104 \cdot 89 \pm 4 \cdot 34 \\
(27,2832) \\
48 \cdot 34 \pm 2 \cdot 49 \\
(67,3239) \\
39 \cdot 92 \pm 5 \cdot 47 \\
(13,519) \\
105 \cdot 29 \pm 5 \cdot 31 \\
(24,2527)
\end{gathered}
$$

\begin{tabular}{|c|c|c|c|c|c|}
\hline \multirow[t]{2}{*}{ Female } & \multicolumn{5}{|c|}{ Male } \\
\hline & $C y$ & $\mathrm{Pm}^{2}$ & $\mathrm{Cy} / \mathrm{Pm}^{2}$ & $\mathrm{Cy}-\mathrm{Pm}^{2}$ & wild \\
\hline Cy & $\begin{array}{l}89 \cdot 87 \pm 2 \cdot 31 \\
(185,16627)\end{array}$ & $\begin{array}{c}98 \cdot 19 \pm 4 \cdot 31 \\
(46,4517)\end{array}$ & $\begin{array}{c}95 \cdot 58 \pm 7 \cdot 00 \\
(19,1816)\end{array}$ & $\begin{array}{c}105 \cdot 71 \pm 6 \cdot 94 \\
(21,2220)\end{array}$ & $\begin{array}{c}111 \cdot 80 \pm 9 \cdot 60 \\
(24,2683)\end{array}$ \\
\hline $\mathrm{Pm}^{2}$ & $\begin{array}{c}95 \cdot 50 \pm 5 \cdot 01 \\
(40,3820)\end{array}$ & $\begin{array}{l}83 \cdot 27 \pm 2 \cdot 25 \\
(131,10908)\end{array}$ & $\begin{array}{c}88 \cdot 70 \pm 4 \cdot 60 \\
(17,1508)\end{array}$ & $\begin{array}{c}108 \cdot 40 \pm 6 \cdot 83 \\
(15,1626)\end{array}$ & $\begin{array}{c}81 \cdot 59 \pm 6 \cdot 58 \\
(22,1795)\end{array}$ \\
\hline $\mathrm{Cy} / \mathrm{Pm}^{2}$ & $\begin{array}{c}62 \cdot 47 \pm 4 \cdot 22 \\
(21,1312)\end{array}$ & $\begin{array}{c}93 \cdot 30 \pm 4 \cdot 67 \\
(23,2146)\end{array}$ & $\begin{array}{c}69 \cdot 58 \pm 2 \cdot 88 \\
(65,4523)\end{array}$ & $\begin{array}{c}63 \cdot 94 \pm 4 \cdot 47 \\
(16,1023)\end{array}$ & $\begin{array}{c}95 \cdot 87 \pm 5 \cdot 81 \\
(23,2205)\end{array}$ \\
\hline $\mathrm{Cy}-\mathrm{Pm}^{2}$ & $\begin{array}{c}79 \cdot 89 \pm 4 \cdot 79 \\
(18,1438)\end{array}$ & $\begin{array}{c}90 \cdot 00 \pm 4 \cdot 01 \\
(24,2160)\end{array}$ & $\begin{array}{c}69 \cdot 14 \pm 3 \cdot 66 \\
(22,1521)\end{array}$ & $\begin{array}{c}85 \cdot 11 \pm 2 \cdot 81 \\
(63,5362)\end{array}$ & $\begin{array}{c}104 \cdot 81 \pm 6 \cdot 35 \\
(27,2830)\end{array}$ \\
\hline wild & $\begin{array}{c}114 \cdot 19 \pm 8 \cdot 00 \\
(21,2398)\end{array}$ & $\begin{array}{c}122 \cdot 09 \pm 6 \cdot 11 \\
(22,2686)\end{array}$ & $\begin{array}{c}120 \cdot 76 \pm 8 \cdot 22 \\
(17,2053)\end{array}$ & $\begin{array}{c}131 \cdot 53 \pm 8 \cdot 24 \\
(17,2236)\end{array}$ & $\begin{array}{c}117 \cdot 14 \pm 2 \cdot 88 \\
(160,18743)\end{array}$ \\
\hline
\end{tabular}

\section{Male}

wild

$$
\left.\begin{array}{c}
111 \cdot 8 \pm 9 \cdot 60 \\
(24,2683) \\
59 \cdot 21 \pm 3 \cdot 42 \\
(28,1658) \\
65 \cdot 07 \pm 5 \cdot 80 \\
(15,988) \\
117 \cdot 14 \pm 2 \cdot 88 \\
(160,18743)
\end{array}\right]
$$

male parameters are closer to 1.0 than the female parameters for all genotypes: a result consistent with the 2 way ANOVA conclusion that females account for more of the variation in fecundity.

Despite the lack of female $\times$ male interaction, genes on the $\mathrm{Cy}$ and $\mathrm{Pm}$ inversions may still interact in either sex to induce fecundity effects that are non-additive or non-multiplicative. Additive and multiplicative epistasis indices and confidence intervals for fecundity of both sexes are tabulated in table 17 using the definitions outlined in the methods section. In general males and females show quantitatively different levels of epistasis, and there are several reversals of sign between the sexes. The additive and multiplicative models are fairly consistent, though there are cases in which a particular genotype shows significant epistasis in one model and not in the other. Whenever a genotype has significant additive epistasis, its multiplicative epistasis is also significant, but not vice versa. The heterogeneous background stocks appear to have more epistasis in fecundity than the homogeneous background stocks, and this is not due to the goodness of fit to the fecundity models. Unlike the viability parameters, fecundity epistasis does not show significant reversal in sign between the two backgrounds.

\section{(iv) Sexual selection}

Each experiment designed after the general paradigm yields a $2 \times 2$ table of the frequency of each mating type. Out of a total of 50 such tables, only 5 
TABLE 16

Estimates of fecundity based on maximum likelihood fits to additive and multiplicative models. The $4 \times 4$ matrices have 9 degrees of freedom (critical chisquare value $=16.919$ ), and the $5 \times 5$ matrices have 16 degrees of freedom (critical chisquare $=26 \cdot 296$ ). Multiplicative parameters listed are $\mathrm{f}_{\mathrm{i}}$ and $\mathrm{m}_{\mathrm{i}}$, while for the additive model $1-\mathrm{f}_{\mathrm{i}}$ and $1-\mathrm{m}_{\mathrm{i}}$ are listed

$4 \times 4$ matrices

Background

Heterogeneous

Homogeneous

Heterogeneous

Homogeneous

$5 \times 5$ matrices

Background

Heterogeneous

Homogeneous

Heterogeneous

Homogeneous

\section{Background}

Heterogeneous

Homogeneous

$\begin{array}{lr}\mathrm{Cy} / \mathrm{Pm}^{1} & 0.036 \pm 0.082 \\ \mathrm{Cy} / \mathrm{Pm}^{2} & -0.006 \pm 0.086 \\ \mathrm{Cy}-\mathrm{Pm}^{2} & 0.064 \pm 0.072\end{array}$

Additive model

\begin{tabular}{cccccc} 
Sex & Cy & $\mathrm{Pm}^{1}$ & $\mathrm{Cy} / \mathrm{Pm}^{1}$ & wild & $\mathrm{G}_{9}$ \\
F & $0.718 \pm 0.027$ & $0.607 \pm 0.023$ & $0.546 \pm 0.023$ & 1.000 & 14.41 \\
M & $0.982 \pm 0.028$ & $0.841 \pm 0.024$ & $0.826 \pm 0.024$ & 1.000 & \\
F & $0.908 \pm 0.029$ & $0.558 \pm 0.022$ & $0.502 \pm 0.021$ & 1.000 & 7.06 \\
M & $0.928 \pm 0.025$ & $0.882 \pm 0.025$ & $0.811 \pm 0.022$ & 1.000 & \\
\multicolumn{7}{c}{ Multiplicative model } \\
F & $0.712 \pm 0.030$ & $0.563 \pm 0.027$ & $0.516 \pm 0.026$ & 1.000 & 11.64 \\
M & $1.025 \pm 0.041$ & $0.779 \pm 0.036$ & $0.773 \pm 0.036$ & 1.000 & \\
F & $0.913 \pm 0.033$ & $0.514 \pm 0.025$ & $0.465 \pm 0.024$ & 1.000 & 9.11 \\
M & $0.926 \pm 0.037$ & $0.885 \pm 0.036$ & $0.753 \pm 0.033$ & 1.000 &
\end{tabular}

Additive model

\begin{tabular}{ccccccc} 
Sex & Cy & $\mathrm{Pm}^{2}$ & $\mathrm{Cy} / \mathrm{Pm}^{2}$ & $C y-\mathrm{Pm}^{2}$ & wild & $\mathrm{G}_{16}$ \\
F & $0.888 \pm 0.027$ & $0.815 \pm 0.026$ & $0.780 \pm 0.025$ & $0.708 \pm 0.024$ & 1.000 & 24.00 \\
M & $0.994 \pm 0.027$ & $0.868 \pm 0.025$ & $0.807 \pm 0.024$ & $1.004 \pm 0.028$ & 1.000 & \\
F & $0.884 \pm 0.027$ & $0.814 \pm 0.026$ & $0.692 \pm 0.024$ & $0.762 \pm 0.025$ & 1.000 & 25.21 \\
M & $0.992 \pm 0.025$ & $1.007 \pm 0.026$ & $0.923 \pm 0.025$ & $1.010 \pm 0.027$ & 1.000 & \\
\multicolumn{7}{c}{ Multiplicative model } \\
F & $0.871 \pm 0.028$ & $0.799 \pm 0.026$ & $0.766 \pm 0.027$ & $0.680 \pm 0.025$ & 1.000 & 23.98 \\
M & $1.009 \pm 0.033$ & $0.860 \pm 0.031$ & $0.777 \pm 0.029$ & $1.034 \pm 0.034$ & 1.000 & \\
F & $0.875 \pm 0.028$ & $0.803 \pm 0.026$ & $0.682 \pm 0.024$ & $0.753 \pm 0.026$ & 1.000 & 26.24 \\
M & $0.921 \pm 0.031$ & $1.014 \pm 0.032$ & $0.925 \pm 0.031$ & $1.034 \pm 0.033$ & 1.000 &
\end{tabular}

\section{TABLE 17}

Measures of fecundity epistasis and confidence intervals

Additive fecundity model

Additive epistasis

Pop.

Female

Male

$\begin{array}{ll}\mathrm{Cy} / \mathrm{Pm}^{1} & 0.221 \pm 0.082^{*} \\ \mathrm{Cy} / \mathrm{Pm}^{2} & 0.077 \pm 0.086 \\ \mathrm{Cy} \mathrm{Pm}^{2} & 0.005 \pm 0.086\end{array}$

$0.003 \pm 0.086$
$-0.055 \pm 0.086$
$0.142 \pm 0.090^{*}$
$0.001 \pm 0.080$
$-0.076 \pm 0.086$
$0.011 \pm 0.088$

Multiplicative epistasis

Female

$0.225 \pm 0.069^{*} \quad 0.001 \pm 0.070$

$0.075 \pm 0.071^{*} \quad-0.067 \pm 0.072$

$-0.022 \pm 0.072 \quad 0.152 \pm 0: 062^{*}$

$$
\begin{array}{cc}
-0.009 \pm 0.052 & -0.009 \pm 0.050 \\
-0.039 \pm 0.061 & -0.079 \pm 0.062^{*} \\
0.057 \pm 0.051^{*} & 0.011 \pm 0.066
\end{array}
$$

Multiplicative fecundity model

Additive epistasis

Background

Heterogeneous

Pop.

Female

Male

$\mathrm{Cy} / \mathrm{Pm}^{1}$

$\mathrm{Cy} / \mathrm{Pm}^{2}$

$0 \cdot 241 \pm 0 \cdot 094^{*}$

$0.096 \pm 0.092^{*}$

$0 \cdot 010 \pm 0.090$

Homogeneous
$\mathrm{Cy} / \mathrm{Pm}^{1} \quad 0.038 \pm 0.094$

$\mathrm{Cy} / \mathrm{Pm}^{2} \quad 0.004 \pm 0.088$

$\begin{array}{ll}\mathrm{Cy}-\mathrm{Pm}^{2} & 0.075 \pm 0.106\end{array}$

$$
\begin{array}{r}
-0.031 \pm 0 \cdot 127 \\
-0.092 \pm 0 \cdot 106 \\
0.165 \pm 0 \cdot 112^{*} \\
-0.058 \pm 0 \cdot 120 \\
-0.010 \pm 0 \cdot 090 \\
0.099 \pm 0.108
\end{array}
$$

Multiplicative epistasis

Female

Male

$0.252 \pm 0.081 * \quad-0.032 \pm 0.098$

$0.096 \pm 0.089^{*} \quad-0.110 \pm 0.091^{*}$

$-0.023 \pm 0.082 \quad 0.176 \pm 0.101^{*}$

$-0.009 \pm 0.055 \quad-0.084 \pm 0.108$

$-0.029 \pm 0.071 \quad-0.010 \pm 0.081$

$0.069 \pm 0.086 \quad 0.102 \pm 0.091^{*}$ 

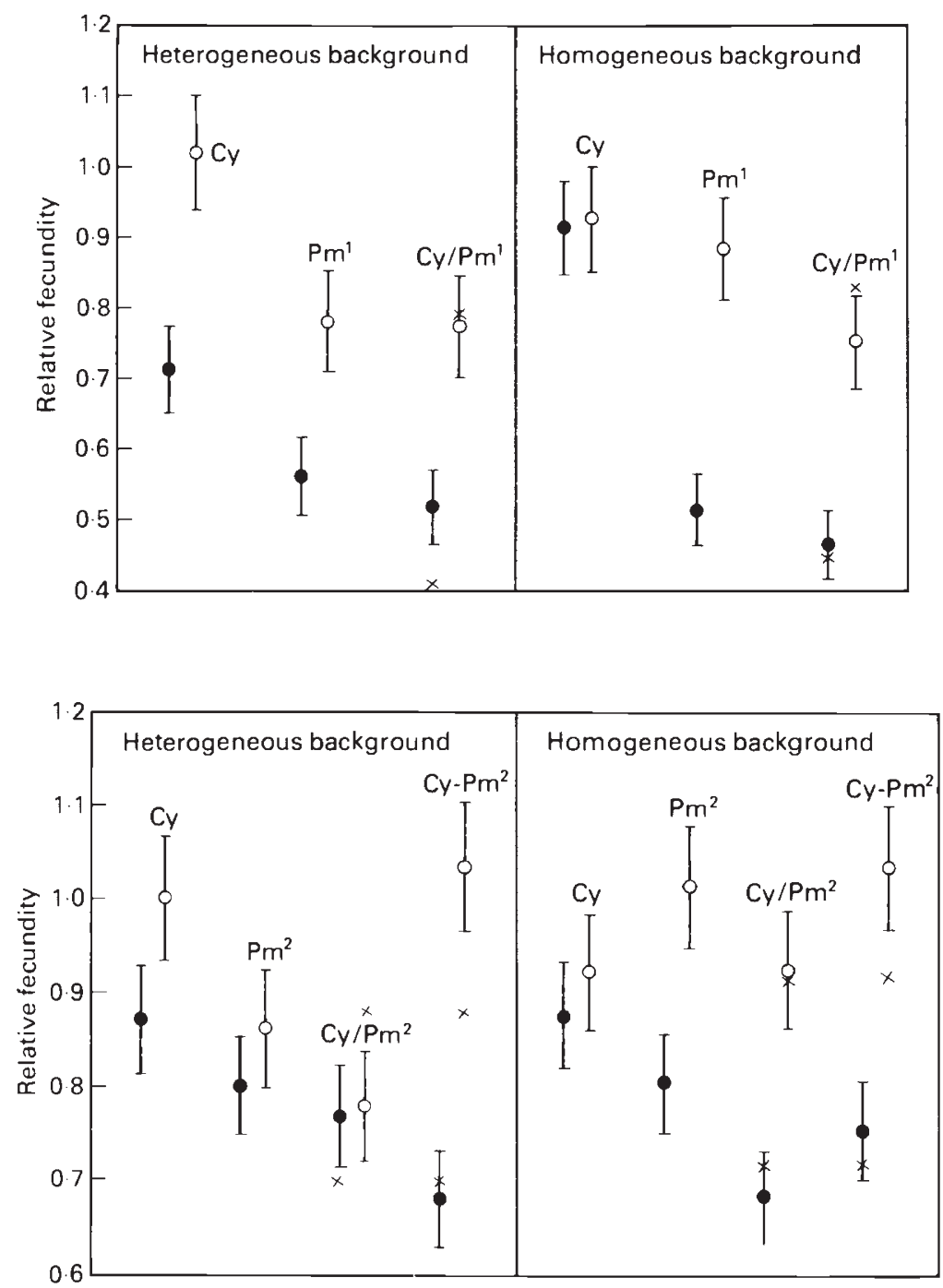

FIG. 4.-Multiplicative fecundity estimates: $\mathrm{Cy}$ and $\mathrm{Pm}^{1}$ stocks are represented above, $\mathrm{Cy}$ and $\mathrm{Pm}^{2}$ stocks below. Means and 95 per cent confidence intervals are plotted. Solid circles represent females and open circles represent males.

were found to exhibit a significant interaction at the 5 per cent level. Since mating types were inferred from progeny phenotypes, mating type sample sizes were smaller than the progeny sample sizes. Estimates of standard errors are in fact approximations based on the assumption of binomial distribution of mate choice. The binomial standard errors are reasonable if variance in mate choice is due to chance alone, while genetic variation is likely to increase the true variance in mate choice. Tables 18 and 19 depict the sexual selection parameters, standard errors and sample sizes for males with the two genetic backgrounds when the two genotypes are present in equal frequency. No differences were seen in the percent of females mated 
TABLE 18

Male sexual selection indices: heterogeneous background. Each index represents the advantage in number of matings of the genotype heading the row over the genotype heading the column. Sample sizes appear in parentheses

\begin{tabular}{|c|c|c|c|c|}
\hline & $\mathrm{Pm}^{1}$ & \multicolumn{2}{|c|}{$\mathrm{Cy} / \mathrm{Pm}^{1}$} & wild \\
\hline $\mathrm{Cy}$ & \multirow[t]{2}{*}{$\begin{array}{c}1 \cdot 229 \pm 0.276 \\
(80)\end{array}$} & \multicolumn{2}{|c|}{$\begin{array}{c}1 \cdot 424 \pm 0 \cdot 323 \\
(80)\end{array}$} & $\begin{array}{c}0.731 \pm 0.221 \\
(45)\end{array}$ \\
\hline $\mathrm{Pm}^{1}$ & & \multicolumn{2}{|c|}{$\begin{array}{c}1 \cdot 208 \pm 0 \cdot 187 \\
(168)\end{array}$} & $\begin{array}{c}0.920 \pm 0.265 \\
(48)\end{array}$ \\
\hline \multirow[t]{2}{*}{$\mathrm{Cy} / \mathrm{Pm}^{1}$} & & & & $\begin{array}{c}0.655 \pm 0 \cdot 140 \\
(91)\end{array}$ \\
\hline & $\mathrm{Pm}^{2}$ & $\mathrm{Cy} / \mathrm{Pm}^{2}$ & $\mathrm{Cy}-\mathrm{Pm}^{2}$ & wild \\
\hline $\mathrm{Cy}$ & {$\left[\begin{array}{c}1 \cdot 280 \pm 0 \cdot 232 \\
(123)\end{array}\right.$} & $\begin{array}{c}1.032 \pm 0.224 \\
(85)\end{array}$ & $\begin{array}{c}0.745 \pm 0.159 \\
(89)\end{array}$ & $\begin{array}{c}0.731 \pm 0.221 \\
(45)\end{array}$ \\
\hline $\mathrm{Pm}^{2}$ & & $\begin{array}{c}0.927 \pm 0 \cdot 158 \\
(138)\end{array}$ & $\begin{array}{c}1 \cdot 114 \pm 0 \cdot 231 \\
(93)\end{array}$ & $\begin{array}{c}0.833 \pm 0.252 \\
(44)\end{array}$ \\
\hline $\mathrm{Cy} / \mathrm{Pm}^{2}$ & & & $\begin{array}{c}1 \cdot 143 \pm 0 \cdot 241 \\
(91)\end{array}$ & $\begin{array}{c}0.984 \pm 0.206 \\
(90)\end{array}$ \\
\hline $\mathrm{Cy}-\mathrm{Pm}^{2}$ & L & & & $\begin{array}{c}0 \cdot 662 \pm 0 \cdot 138 \\
(94)\end{array}$ \\
\hline
\end{tabular}

(it was over 90 per cent for all genotypes) so the data on female mating success are not reported. Consistency of sexual selection parameters was verified using a method analogous to that for viabilities. It has often been observed that a male genotype with low mating success has improved chances when made rare in a population. Dependence of male mating success on male genotype frequency was tested by varying the initial frequency of phenotypes introduced into the mating chamber. Rare male mating advantage was generally observed, but the details are not reported here.

TABLE 19

Male sexual selection indices: homogeneous background

$\mathrm{Pm}^{1} \quad \mathrm{Cy} / \mathrm{Pm}^{1}$ wild

\begin{tabular}{|c|c|c|c|c|}
\hline Cy & \multirow[t]{2}{*}{$\begin{array}{c}1.473 \pm 0 \cdot 260 \\
(133)\end{array}$} & \multicolumn{2}{|c|}{$\begin{array}{c}1 \cdot 484 \pm 0 \cdot 345 \\
(77)\end{array}$} & $\left.\begin{array}{c}0.913 \pm 0.195 \\
(88)\end{array}\right]$ \\
\hline $\mathrm{Pm}^{1}$ & & \multicolumn{2}{|c|}{$\begin{array}{c}0.775 \pm 0.185 \\
(71)\end{array}$} & $\begin{array}{c}0 \cdot 765 \pm 0 \cdot 162 \\
(90)\end{array}$ \\
\hline \multirow[t]{2}{*}{$\mathrm{Cy} / \mathrm{Pm}^{1}$} & & & & $\begin{array}{c}0 \cdot 760 \pm 0 \cdot 163 \\
(88)\end{array}$ \\
\hline & $\mathrm{Pm}^{2}$ & $\mathrm{Cy} / \mathrm{Pm}^{2}$ & $\mathrm{Cy}-\mathrm{Pm}^{2}$ & wild \\
\hline $\mathrm{Cy}$ & {$\left[\begin{array}{c}0 \cdot 937 \pm 0 \cdot 138 \\
(184)\end{array}\right.$} & $\begin{array}{c}0.977 \pm 0.209 \\
(87)\end{array}$ & $\begin{array}{c}0.913 \pm 0 \cdot 194 \\
(88)\end{array}$ & $\begin{array}{c}0.913 \pm 0.195 \\
(88)\end{array}$ \\
\hline $\mathrm{Pm}^{2}$ & & $\begin{array}{c}1 \cdot 300 \pm 0 \cdot 273 \\
(92)\end{array}$ & $\begin{array}{c}1 \cdot 400 \pm 0 \cdot 304 \\
(84)\end{array}$ & $\begin{array}{c}0.979 \pm 0.201 \\
(95)\end{array}$ \\
\hline $\mathrm{Cy} / \mathrm{Pm}^{2}$ & & & $\begin{array}{c}0.946 \pm 0.223 \\
(72)\end{array}$ & $\begin{array}{c}0 \cdot 756 \pm 0 \cdot 180 \\
(72)\end{array}$ \\
\hline $\mathrm{Cy}-\mathrm{Pm}^{2}$ & L & & & $\begin{array}{c}0 \cdot 561 \pm 0 \cdot 124 \\
(89)\end{array}$ \\
\hline
\end{tabular}


TABLE 20

Epistasis in male sexual selection. Odds ratio tests

Heterogeneous background Population Additive

Odds ratio

$\mathrm{Cy} / \mathrm{Pm}^{3}$

$\mathrm{Cy} / \mathrm{Pm}^{2}$

$\mathrm{Cy}-\mathrm{Pm}^{2}$

$$
0.004
$$

$$
0.420
$$

0.098

Multiplicative
-0.026
0.480
0.083

0.083
Odds ratio

1.026

$89808 \cdot 3^{* * *}$

$1 \cdot 013$

Homogeneous background

$\begin{array}{lcccc}\text { Population } & \text { Additive } & \text { Odds ratio } & \text { Multiplicative } & \text { Odds ratio } \\ \text { Cy } / \mathrm{Pm}^{1} & 0.082 & 1.464 & 0.084 & 1.238 \\ \mathrm{Cy} / \mathrm{Pm}^{2} & -0.136 & 3.090 & -0.167 & 3.152 \\ \mathrm{Cy}-\mathrm{Pm}^{2} & -0.331 & 5066.69^{* *} & -0.465 & 5888.68^{* *}\end{array}$

Deviations of sexual selection indices of double heterozygotes (relative to wild type) from the sum or product of single heterozygote indices suggest additive or multiplicative epistasis at the level of sexual selection. Odds ratio tests for the significance of epistasis in sexual selection are reported in table 20. Among flies with the heterogeneous background, the $\mathrm{Cy} / \mathrm{Pm}^{2}$ males had a significantly higher mating index than expected, indicating positive additive and multiplicative epistasis. The Cy- $\mathrm{Pm}^{2}$ males with the homogeneous background show significant negative epistasis in mating success. In both backgrounds the cis males had a lower mating success than trans males, but the difference between backgrounds in the pattern of epistasis is striking.

\section{(v) Population prediction}

Using the system of recursions in the Methods section, it is possible to predict population behavior for any inital condition and set of viabilities, fecundities and sexual selection parameters. The accuracy of these predictions was assessed by comparing them to actual selection experiments using the same stocks of Drosophila (Clark et al., 1981). Since there is sampling error in such a selection experiment, replicates tend to deviate from one another. Multinomial sampling of predicted trajectories were performed each generation with a sample size equal to the mean of the observed selection sample size. By generating 100 such trajectories and plotting the third and ninety-eighth, we obtained a 96 per cent empirical confidence region for the allele frequencies. Results are plotted in figs. 5 and 6. Populations which had one chromosome segregating fell consistently within these predicted regions. Populations with both $\mathrm{Cy}$ and $\mathrm{Pm}$ segregating were more heterogeneous, but the predicted curves still generally contained the observations.

\section{DisCUSSION}

The observed experimental variance in most tests of selection components are quite high, necessitating very large sample sizes to obtain satisfactory resolution. We define resolving power as the difference $d$ between the means of two fitness estimates, assuming the two estimates have 

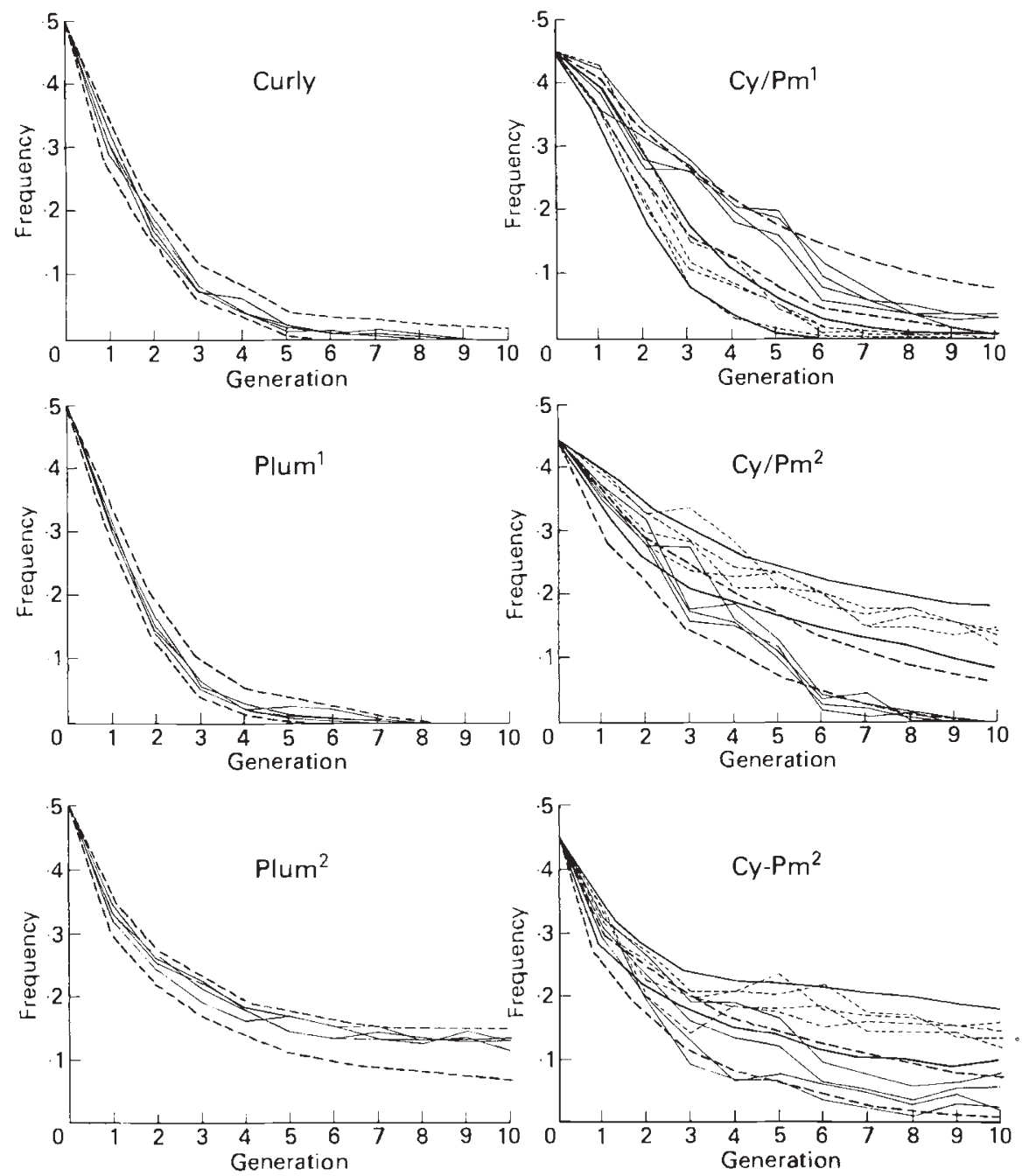

FIG. 5.-Selection experiments: heterogeneous background. Dashed lines represent Plum frequency, while solid lines represent Curly frequency. Trajectories of 4 replicate experiments are plotted (see Clark et al. 1981 for initial conditions). 96 per cent empirical confidence intervals on the trajectories are plotted. They are based on the selection components estimates and multinomial sampling (see text).

the same variance, such that we have a 95 per cent chance of detecting the difference at a 95 per cent level of confidence. If $\alpha$ is the level of confidence, $n$ the sample size for each estimate, $s$ the sample standard deviation, and $P$ is the probability of detecting a difference, then the resolving power is:

$$
d=(s / n)\left[t_{(\alpha, n)}+t_{(2 \cdot 2 p, n)}\right]
$$

as shown by Snedecor and Cochran (1967). Using typical values of standard errors and sample sizes, the resolving powers for the four components were: meiotic drive $15 \cdot 3$ per cent, viability $7 \cdot 2$ per cent, fecundity $18 \cdot 0$ per cent, 

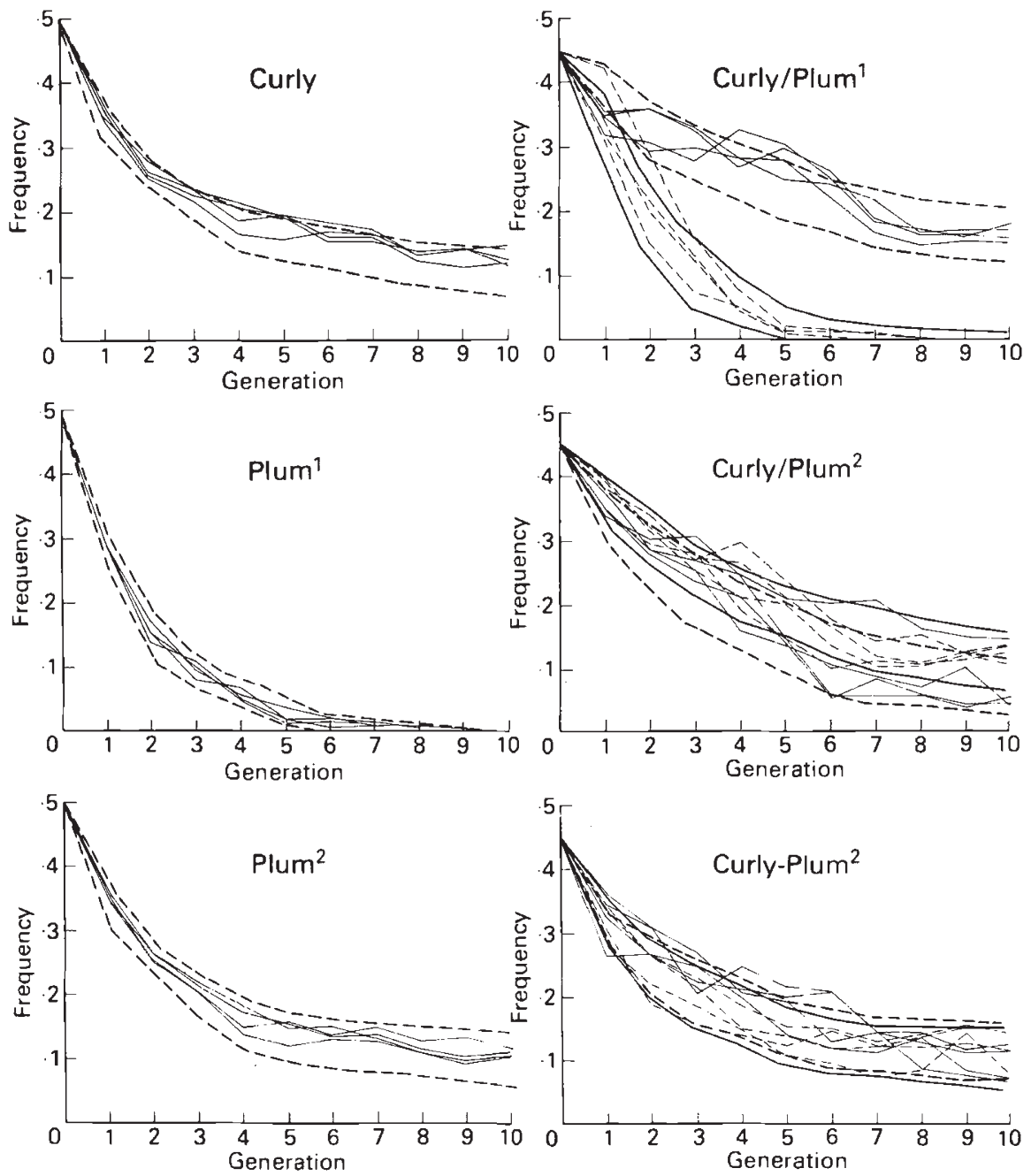

Fig. 6.-Selection experiments: homogeneous background.

and sexual selection $20 \cdot 2$ per cent. Our experimental design, using phenotypically visible lethal alleles, minimized the work involved in scoring phenotypes, and made collection of fairly large sample sizes practical. Even so our resolution was rather weak. Even with a massive effort, the chances of being able to detect differences in fitness components among electrophoretic variants whose true fitnesses differ by 1 per cent are, as Lewontin (1974) stated, miniscule.

In addition to the statistical problem of large variances, the experimental design of selection components analysis may be inherently incapable of resolving the four components. For example, the methods of Christiansen and Frydenburg (1973) confound male gametic and sexual selection, since they cannot distinguish between a mating advantage of one genotype of 
male, and meiotic drive favoring that allele in gametes of heterozygous males. In our design we cannot always resolve maternal effects in viability and meiotic drive. Equal segregation ratios from the crosses $\mathrm{Cy} \times \mathrm{Cy}$, $\mathrm{Cy} \times$ wild, and wild $\times$ Cy could be explained by combinations of meiotic drive and viability, but after tempering our inference by the biological knowledge that equal distortion in both sexes is unlikely, we conclude that no meiotic drive is operating.

Since fecundity was assessed by counting adult progeny, it may seem that this would confound fecundity with viability selection. Our method of scoring fecundity was chosen in order to save the effort involved in counting eggs, and more important, because we wish to make a distinction between absolute and relative viability. In particular, we consider variation in absolute viability as a component of female fecundity, a choice based on the results of Chapco and Ebisuzaki (1978) and Chapco (1979) who estimated that 70 per cent of the variance in egg-to-adult survival (i.e., absolute viability) in Drosophila is due to the maternal genotype. As an example, consider the reciprocal crosses $\mathrm{Cy} \times$ wild and wild $\times \mathrm{Cy}$. Suppose each female lays 100 eggs and the relative viability of $\mathrm{Cy}$ and wild is 1.0 . If the $\mathrm{Cy}$ female has an egg hatchability of 50 per cent, then we would observe $25 \mathrm{Cy}$ and 25 wild progeny on day 18 , while if the egg hatchability of the wild female is 100 per cent, we would observe $50 \mathrm{Cy}$ and 50 wild type progeny. Had we assessed fecundity by counting eggs and viability as segregation ratios, we would have missed the important contribution of maternally determined absolute viability. By scoring fecundity as we did, we get the more accurate picture that the $\mathrm{Cy}$ females contributed one-half the number of mature progeny. Our methods are justified by the excellent correspondence between observed and predicted selection dynamics.

Selection components analysis assumes homogeneity of selection parameters in time and space. Age dependence of viability can often be tested, and by observing segregation ratios through emergence dates we found none. On the other hand, Christiansen et al. (1977) demonstrated age dependence in viability between esterase variants in the eelpout. The productivity of a female Drosophila after one insemination is a good predictor of her lifetime productivity (Gowen, 1952; McMillan et al.,1970), so fecundity may also be age independent. Egg hatchability on the other hand may be determined by maternal age. Components of mate choice are probably determined by age and past experience (Pruzan, 1976), and the problem of multiple mating is not trivial.

Now we will return to the experimental results and consider the significance of interaction at the four levels of fitness. There were two cases in which reciprocal crosses yielded different segregation ratios: the $\operatorname{Pm}^{1} \times$ wild and $\mathrm{Cy} / \mathrm{Pm}^{1} \times$ wild crosses with the heterogeneous background. If maternal effects caused the deviations, then the $\mathrm{Pm}^{1} /+$ genotype appears to have a higher viability in the wild cytoplasm in the $\mathrm{Pm}^{1}$ : wild test, but the $\mathrm{Pm}^{1} /+$ genotype has a lower viability relative to $\mathrm{Cy} /+$ in the wild cytoplasm in the $\mathrm{Cy}: \mathrm{Pm}^{1}$ test (see table 5). This inconsistency cannot be resolved by invoking meiotic drive, since the direction of distortion would have to reverse in the two crosses. The fact that these reciprocal cross differences disappear in the homogeneous background leads us to believe that they may be an artifact of the background genotypes. We therefore conclude that no meiotic drive is operating. 
Generally meiotic drive is assessed by examining segregation ratios with respect to a single locus. In reality, meiotic drive is a property of chromosome pairs, so observed segregation ratios may be a result of interactions between genes. A good example of this kind of epistasis in meiotic drive is the SD-Rsp system (see Hartl and Hiraizumi, 1976 for review), in which the observed segregation distortion depends on the genotype at several loci. When meiotic drive is the only force causing gene frequency changes in a one locus two allele system, fixation of the driven allele is rapid, but if more alleles are added, or if more loci are involved the population dynamics can be quite complex. The significance of epistasis in meiotic drive is not known, but there is evidence indicating that segregation distortion may not be rare in natural populations of Drosophila. Hiraizumi and Crow (1960) observed that 6 out of 183 second chromosomes showed strong segregation distortion, and since then there have been a number of studies indicating the prevalence of distorted segregation (Katz, 1979).

Strong selection occurred at the viability stage, with a range in relative viabilities of 0.464 to $1 \cdot 00$. With few exceptions, different crosses yielded consistent estimates of viability, and environmental effects of density and larval competition were small. Comparisons between heterogeneous and homogeneous background stocks show that there is strong interaction with the genetic background. Pairwise tests show that the $\mathrm{Pm}^{1}, \mathrm{Cy} / \mathrm{Pm}^{1}$, and $\mathrm{Pm}^{2}$ viabilities do not differ but the three genotypes bearing Cy have significantly different viabilities in the two backgrounds. The $\mathrm{Cy} /+$ genotype viability is lower in the heterogeneous background, while the two double heterozygotes have a higher viability in the heterogeneous background. These differences are reflected in the selection experiment trajectories, and background interactions are seen in fecundity and sexual selection as well.

Over half of the tests of epistasis in viability were significant. In the heterogeneous background, there was positive additive epistasis in the $\mathrm{Pm}^{2}$ bearing double heterozygotes, while in the homogeneous background, negative epistasis was seen in $\mathrm{Cy} / \mathrm{Pm}^{2}$. This reversal in the direction of epistasis indicates an interaction with the background, and it is surprising in light of the fact that the homogeneous background stocks were derived from the heterogeneous background stocks. The cis and trans double heterozygotes in the homogeneous background manifest different levels of epistasis, and in fact their mean viabilities are significantly different. It appears then, that these structural rearrangements result in position effects in viability.

Mean fecundities varied from 36.17 progeny per female to 131.53 progeny per female, representing a 3.64 fold difference. When the mating type fecundities are partitioned into separate male and female effects this range is smaller. Among females the most fecund genotype has a fecundity 1.80 times the lowest, while among males this ratio is 1.33 . The only consistent pattern in fecundities (fig. 4) is that the relative fecundities of males are closer to $1 \cdot 0$ than the females of the same genotype, indicating that the femaie component was more important than the male fecundities. Interactions with the background resulted not only in changes of relative fecundity among genotypes, but also among sexes. In the top half of fig. 4, the male and female $C y$ relative fecundities are quite different in the heterogeneous background, but identical in the homogeneous background. The biggest difference between heterogeneous and homogeneous back- 
grounds is the Cy female fecundity, which was much higher in the homogeneous background. This is consistent with the background interaction in viabilities and the selection experiment results. The change in relative fecundity of Cy females is not so apparent in the bottom half of fig. 4, where fecundities are estimated relative to $\mathrm{Pm}^{2}$ bearing genotypes.

Table 17 demonstrates that the significance of epistasis in fecundity is highly model dependent. Including the additive and multiplicative measures of epistasis as well as position effects in fecundity, the number of possible interaction parameters is large. We can nevertheless be convinced that epistasis in fecundity is important, because 8 of the 24 tests of epistasis were significant in females, and 7 out of 24 tests showed significant epistasis in males. The direction of epistasis occasionally reversed between sexes, but there were no cases in which epistasis showed a significant reversal between backgrounds.

Sexual selection indices vary by a factor of $1 \cdot 78$, supporting the general observation that sexual selection is a more important component of male fertility than is fecundity (Prout, 1969; Bungaard and Christiansen, 1972). Comparisons between the heterogeneous and homogeneous background indices reveal a similar pattern to the pattern of female fecundities. The direction of epistasis is reversed in the two backgrounds, again suggesting that the genetic background plays a considerable role in the expression of the genes on the Cy and Pm inversions.

It is of interest to see to what extent the selective effects of the inversions are correlated among components. Watanabe and Oshima (1973) studied productivity and viability of wild second chromosomes using Cy-Pm techniques, and found a correlation between sexes in productivity, and a correlation between productivity and viability in males but not females. Clegg, Kahler and Allard (1978), on the other hand saw numerous cases of reversal of the direction of selection among components. We observe a high correlation between sexes in viability and fecundity, but not in sexual selection. Correlations between components are somewhat weaker, and in some instances reverse in order. Perhaps more surprising is the fact that the sign of epistasis in viability is in several cases the opposite of the fecundity epistasis. The significance of this remains an interesting theoretical problem.

The selection experiments reveal a number of important points about the expression of epistasis and the background effects. In the previous paper (Clark et al., 1981), we showed that the selection trajectories could be adequately fitted with a model which split the fitness of each genotype into two parameters. In this paper, we split the fitnesses into four components, each of which may depend on sex, and showed that the fit to the selection trajectories is also good. These two methods differ considerably in their approach: the former seeks to obtain the best statistical fit while the latter is an attempt to measure biologically meaningful components. The complexity in the pattern of epistasis (table 21) illustrates the pleiotropic effects of the inversions studied. We emphasize that we did not exhaust the complexity. Development stage dependent viability (e.g., egg hatchability) was not studied, and our summary viability statistics may be overlooking interactions at these stages. The many differences in the fitness components and measures of epistasis seen between the two backgrounds convince us that any measure of relative fitness of one genotype to another is merely a 
TABLE 21

Summary of significant epistasis parameters. + indicates significant positive epistasis (either additive or multiplicative), and - indicates significant megative epistasis

\begin{tabular}{lcccccc} 
& \multicolumn{3}{c}{ Heterogeneous background } & \multicolumn{3}{c}{ Homogeneous background } \\
& $\mathrm{Cy} / \mathrm{Pm}^{1}$ & $\mathrm{Cy} / \mathrm{Pm}^{2}$ & $\mathrm{Cy}-\mathrm{Pm}^{2}$ & $\mathrm{Cy} / \mathrm{Pm}^{1}$ & $\mathrm{Cy} / \mathrm{Pm}^{2}$ & $\mathrm{Cy}-\mathrm{Pm}^{2}$ \\
Viability & - & + & + & - & - & - \\
Female fecundity & + & + & 0 & 0 & 0 & + \\
Male fecundity & 0 & - & + & 0 & - & + \\
Male sex. sel. & 0 & + & 0 & 0 & 0 & -
\end{tabular}

measurement of marginal fitness, and the picture can change drastically when genes at other loci are also included.

The paradox that remains is that gene pair linkage disequilibrium is rarely observed in natural populations, yet epistasis is commonly found in quantitative traits related to fitness and in homozygous chromosome studies. Documented cases of fitness interactions generally involve large blocks of genes, and absence of linkage disequilibrium between particular pairs of genes should not be cited as evidence that there is no interaction. The situation only seems paradoxical in light of our understanding of two locus viability selection, which predicts linkage disequilibrium for a number of epistatic viability matrices. The relationship between gene correlations and epistasis will not be clear until models allowing gene interaction in fertility are characterized. Many one locus fertility and sexual selection models give Hardy-Weinberg genotype frequencies at equilibrium (Penrose, 1949; O'Donald, 1980), and by analogy, epistatic two locus fertility models may be much less likely to generate disequilibrium.

Acknowledgements.-The authors wish to thank F. B. Christiansen for discussion and helpful comments. This work was supported by NIH grants GM28016, GM10452 and NSF grant DEB 77-05747.

\section{REFERENCES}

BROADHURST, P. L., AND JINKS, J. L. 1974. What genetical arhitecture can tell us about the natural selection of behavioral traits. In The Genetics of Behavior, ed. J. H. F. Abeelen. North Holland Publishing Co., Amsterdam.

BUNGAARD, J., AND CHRISTIANSEN, F. B. 1972. Dynamics of polymorphisms. I, Selection components in an experimental population of Drosophila melanogaster. Genetics, 71, 439-460.

CHAPCO, w. 1979. Correlation between chromosome segments and fitness in Drosophila melanogaster. II. The X chromosome and egg viability. Genetics, 92, 595-601.

CHAPCO, W., AND EBISUZAKI, M. M. 1978. Fertility components and maternal effects. Dros. Inf. Serv., 53, 158-159.

CHRISTIANSEN, F. B., AND FRYDENBURG, O. 1973. Selection component analysis of natural polymorphisms using population samples including mother-offspring combinations. Theor. Pop. Biol., 4, 425-445.

CHRISTIANSEN, F. B., FRYDENBURG, O., AND SIMONSEN, v. 1977. Genetics of Zoarces populations. X. Selection components analysis of Esterase III polymorphism using samples of successive cohorts. Hereditas, 87, 129-150.

CLARK, A. G., FELDMAN, M. W., AND CHRISTIANSEN, F. B. 1981. The estimation of epistasis in components of fitness in experimental populations of Drosophila melanogaster. I. A two-stage maximum likelihood model. Heredity, 46, 321-346. 
CLEGG, M. T., KAHLER, A. L., AND ALLARD, R. W. 1978. Estimation of life cycle components of selection in an experimental plant population. Genetics, 89, 765-792.

CURTSINGER, J., AND FELDMAN, M. W. 1980. Experimental and theoretical analysis of the "sex ratio" polymorphism in Drosophila pseudoobscura. Genetics, 94, 445-466.

ENGELS, W. R. 1979. The estimation of mutation rates when premeiotic events are involved. Envir. Mutagenesis, 1, 37-43.

Gowen, J. w. 1952. Hybrid vigor in Drosophila. In Heterosis, ed. J. W. Gowen. Iowa State College Press, Ames.

HARTL, D. L., AND HIRAIZUMI, Y. 1976. Segregation distortion. In The Genetics and Biology of Drosophila, Vol. 1b, eds. M. Ashburner and E. Novitski. Academic Press, New York.

HIRAIZUMI, Y., AND CROW, J. 1960. Heterozygous effects on viability, fertility, rate of development, and longevity of Drosophila chromosomes that are lethal when homozygous. Genetics, 45, 1071-1084.

KATZ, A. J. 1979. Estimation of fitness components of Drosophila melanogaster. II. Influence of reduced transmission frequency. Genetics, 91, 359-368.

KEARSEY, M. J., AND KOJIMA, K. 1967. The genetic architecture of body weight and egg hatchability in Drosophila melanogaster. Genetics, 56, 23-57.

KELLER, R. C., AND MITCHELL, D. G. 1964. Interchromosomal genotypic interactions in Drosophila. II. An analysis of viability characters. Genetics 49, 293-307.

Kendall, M. G. AND StUART, A. 1958. The Advanced Theory of Statistics, Vol. 1. Charles Griffin and Co., London.

KOSUDA, K. 1971. Synergistic interaction between second and third chromosomes in viability in Drosophila melanogaster. Jap. J. Genet., 49, 41-52.

LEWONTIN, R. C. 1974. The Genetic Basis of Evolutionary Change. Columbia University Press, New York.

MATHER, K. 1973. Genetical Structure of Populations. Chapman and Hill, London.

MCMILLAN, M., FITZ-EARLE, M., BUTLER, L., AND ROBSON, D. S. 1970. Quantitative genetics of fertility. II. Lifetime egg production of Drosophila melanogaster: experimental. Genetics, 65, 355-369.

MITCHELL, J. A., AND SIMMONS, M. J. 1977. Fitness effects of EMS induced mutations on the X chromosome of $D$. melanogaster. II. Hemizygous fitness effects. Genetics, 87, 775-783.

O'DONALD, P. 1980. Genetic Models of Sexual Selection. Cambridge University Press.

ØSTERGAARD, H., AND CHRISTIANSEN, F. B. 1980. Selection components analysis of natural polymorphisms using population samples including mother-offspring combinations II. Theor. Pop. Biol., In press.

PENROSE, L. S. 1949. The meaning of fitness in human populations. Ann. Eugenics, 14, 301-304.

PROUT, T. 1965. The estimation of fitness from genotypic frequencies. Evolution, 19, 546-551; 1969. The estimation of fitnesses from population data. Genetics, 63, 949-967; 1971 a. The relation between fitness components and population prediction in Drosophila. I. Estimation of fitness components. Genetics, 68, 127-149; 1971b. The relation between fitness components and population prediction in Drosophila. II. Population prediction. Genetics, 68, 151-167.

PRUZAN, A. 1976. Effects of age, rearing, and mating experience on frequency dependent selection in Drosophila pseudoobscura. Evolution, 30, 130-145.

SEAGER, R. D. 1979. Genetic load and fitness interactions in Drosophila melanogaster. Ph.D. thesis, University of California at Davis.

SIMMONS, M. J., SHELDON, E. W., AND CROW, J. F. 1978. Heterozygous effects on fitness of EMS treated chromosomes in Drosophila melanogaster. Genetics, 88, 575-590.

SNEDECOR, G. W., AND Cochran, w. G. 1967. Statistical Methods, 6th ed. Iowa State University Press, Ames, Iowa.

SPASSKY, B., DOBZHANSKY, TH., AND ANDERSON, W. W. 1965. Genetics of natural populations. XXXVI. Epistatic interactions of the components of the genetic load in Drosophila pseudoobscura. Genetics, 52, 653-664.

SVED, J. A. 1971. An estimation of heterosis in Drosophila melanogaster. Genet. Res., 18, 97-105; 1975. Fitness of third chromosome homozygotes in Drosophila melanogaster. Genet. Res., 25, 197-200.

SVED, J. A., AND AYALA, F. J. 1970. A population test for heterosis in Drosophila pseudoobscura. Genetics, 66, 97-113.

TEMIN, R. G., MEYER, H. U., DAWSON, P. S., AND CROW, J. F. 1969. The influence of epistasis on homozygous viability depression in Drosophila melanogaster. Genetics, 61, 497-519. 
TRACEY, M., AND AYALA, F. J. 1974. Genetic load in natural populations. Is it compatible with the hypothesis that many polymorphisms are maintained by natural selection?. Genetics, $77,569-589$.

TSUNO, K. 1970. Analysis of genetic variability in the two major autosomes of Drosophila melanogaster in a natural and a cage population. Jap. J. Genet., 45, 87-100.

WATANABE, T. T., AND OSHIMA, C. 1973. Fertility genes in natural populations of Drosophila melanogaster. II. Correlation between productivity and viability. Japan. J. Genet., 48, 337-347.

WILSON, J. 1968. Experimental determination of fitness interactions in Drosophila melanogas ter by the method of marginal populations. Genetics, 59, 501-511. 